\title{
MicroRNA-mediated responses to long- term magnesium-deficiency in Citrus sinensis roots revealed by Illumina sequencing
}

Wei-Wei Liang ${ }^{1}$, Jing-Hao Huang ${ }^{1,2}$, Chun-Ping Li ${ }^{1}$, Lin-Tong Yang ${ }^{1}$, Xin Ye ${ }^{1}$, Dan Lin ${ }^{1}$ and Li-Song Chen ${ }^{1,3,4^{*}}$

\begin{abstract}
Background: Magnesium (Mg)-deficiency occurs most frequently in strongly acidic, sandy soils. Citrus are grown mainly on acidic and strong acidic soils. Mg-deficiency causes poor fruit quality and low fruit yield in some Citrus orchards. For the first time, we investigated Mg-deficiency-responsive miRNAs in 'Xuegan' (Citrus sinensis) roots using Illumina sequencing in order to obtain some miRNAs presumably responsible for Citrus Mg-deficiency tolerance.

Results: We obtained 101 (69) miRNAs with increased (decreased) expression from Mg-starved roots. Our results suggested that the adaptation of Citrus roots to Mg-deficiency was related to the several aspects: (a) inhibiting root respiration and related gene expression via inducing miR158 and miR2919; (b) enhancing antioxidant system by downregulating related miRNAs (miR780, miR6190, miR1044, miR5261 and miR1151) and the adaptation to low-phosphorus (miR6190); (c) activating transport-related genes by altering the expression of miR6190, miR6485, miR1044, miR5029 and miR3437; (d) elevating protein ubiquitination due to decreased expression levels of miR1044, miR5261, miR1151 and miR5029; (e) maintaining root growth by regulating miR5261, miR6485 and miR158 expression; and (f) triggering DNA repair (transcription regulation) by regulating miR5176 and miR6485 (miR6028, miR6190, miR6485, miR5621, miR160 and miR7708) expression. Mg-deficiency-responsive miRNAs involved in root signal transduction also had functions in Citrus Mg-deficiency tolerance.
\end{abstract}

Conclusions: We obtained several novel Mg-deficiency-responsive miRNAs (i.e., miR5261, miR158, miR6190, miR6485, miR1151 and miR1044) possibly contributing to Mg-deficiency tolerance. These results revealed some novel clues on the miRNA-mediated adaptation to nutrient deficiencies in higher plants.

Keywords: Citrus sinensis, Illumina sequencing, Magnesium-deficiency, miRNA, Root

\section{Background}

Magnesium (Mg)-deficiency, a common problem in many agricultural crops, occurs most frequently in strongly acidic, sandy soils, where $\mathrm{Mg}$ is very prone to leaching [1]. Citrus are grown mainly on acidic and strong acidic soils and Mg-deficiency is responsible for

\footnotetext{
* Correspondence: lisongchen2002@hotmail.com; lisongchen@fafu.edu.cn 'Institute of Plant Nutritional Physiology and Molecular Biology, College of Resources and Environment, Fujian Agriculture and Forestry University, Fuzhou 350002, China

${ }^{3}$ Fujian Provincial Key Laboratory of Soil Environmental Health and Regulation, College of Resources and Environment, Fujian Agriculture and Forestry University, Fuzhou 350002, China

Full list of author information is available at the end of the article
}

the poor fruit quality and the reduction in fruit yield in some Citrus orchards [2]. According to our investigation in 2011 , over $90 \%$ and $77 \%$ of Citrus grandis orchard soils from Pinghe county, Fujian province had a pH less than 5.0 and a soil exchange $\mathrm{Mg}$ content less than the optimum range, respectively [3]. What's worse, crop Mgdeficiency, which is becoming more and more popular due to soil acidification and improper farmer practices such as intensive crop production systems and highly fortified rotation, has been considered to be an urgent agricultural problem [3,4]. Although $\mathrm{Mg}$ is one of the most important nutrients in higher plants and plays essential roles in numerous cellular processes such as 
chlorophyll biosynthesis, gas exchanges [2, 5-7], conformational stabilization of proteins, nucleic acids, cell walls and membranes [8], partitioning and utilization of photoassimilates $[7,9]$, activation of enzymes $[9,10]$ and reactive oxygen species (ROS) generation [9]. Despite the important roles of $\mathrm{Mg}$ in higher plants, $\mathrm{Mg}$ has been less paid attention by agronomists and botanists relative to the other nutrients and is considered to be "the forgotten element" $[4,11]$. Therefore, it is very important to elucidate the molecular mechanisms on Mg-deficiency impairments and tolerance in higher plants. To our knowledge, such data are rare $[10,12,13]$.

Evidence demonstrates that microRNA (miRNA)-mediated posttranscriptional regulation of gene expression plays a role in plant adaptive responses to deficiencies of phosphorus $(\mathrm{P})$, potassium $(\mathrm{K})$, nitrogen $(\mathrm{N})$, sulfur $(\mathrm{S})$, manganese $(\mathrm{Mn})$, boron $(\mathrm{B})$, zinc $(\mathrm{Zn})$ and iron $(\mathrm{Fe})$ [14-20]. Numerous differentially expressed miRNAs have been isolated from P-starved Arabidopsis, white lupin, Medicago truncatula, common bean, rice, barley, tomato and soybean [21-25]. The roles of P-deficiencyinduced up-regulation of plant miR399 and miR827 in the maintenance of $\mathrm{P}$ homeostasis via inhibiting their targets ubiquitin-conjugating enzyme E2 24 (UBC24) and $N$ limitation adaptation (NLA), respectively have been well characterized [14, 23, 26, 27].

Nitrogen-deficiency-induced alterations of miRNA profiles have been reported on several higher plants including maize, Arabidopsis, soybean, common bean $[20,24,25,28,29]$. Several N-deficiency-responsive miRNAs have been characterized in some details. For example, root modulation under $\mathrm{N}$-deficiency was coordinated by miR160, miR167 and miR171 and root growth was promoted by down-regulating miR167 expression and up-regulating miR160 and miR171 expression [24, 28]. N-deficiency-induced down-regulation of miR169 has been demonstrated to be an adaptive strategy of plants to $\mathrm{N}$-starvation via $\mathrm{N}$-uptake and remobilization [24, 30].

Despite the vital roles of $\mathrm{K}$ in higher plants, little is known about K-deficiency-responsive miRNAs. In a study, Yan et al. [31] examined K-deficiency-induced alterations in expression of miR444a and its targets (i.e., MADS-57, $M A D S-27 b, M A D S-27 a$ and MADS-23) in rice roots, and found that miR444a was slightly down-regulated and $M A D S-23$ was greatly up-regulated.

In addition, many differentially expressed miRNAs have been identified in B-deprived $C$. sinensis roots and leaves [17, 18], Cu-starved [32] and Fe-deficient [33] Arabidopsis, S-deprived Brassica rapus [34], Mn-limited Phaseolus vulgaris [25] and Zn-deficient Sorghum bicolor [35].

Although the effects of nutrient deficiencies on miRNA expression in higher plants have been explored by some workers, most of these studies have been paid to herbaceous plants. Little is known about $\mathrm{Mg}$ deficiency-induced alterations of miRNA expression in woody plants. Previously, we examined Mg-deficiencyresponsive miRNAs in $C$. sinensis leaves revealed by Illumina sequencing and identified 71 down- and 75 up-regulated miRNAs, implying the potential roles of miRNAs in Citrus Mg-deficiency tolerance [36]. On this basis, we used Illumina sequencing to sequence two small RNA libraries from Mg-sufficient (control) and -deficient $C$. sinensis roots in order to distinguish the differences in Mg-deficiency-induced alterations of miRNA profiles between $C$. sinensis roots and leaves and to obtain some miRNAs presumably responsible for Citrus Mg-deficiency tolerance.

\section{Results}

Root dry weight (DW) and root and leaf Mg

Root DW and root and leaf Mg levels were lower in $0 \mathrm{mM} \mathrm{Mg}$-treated seedlings than in $1 \mathrm{mM} \mathrm{Mg-treated}$ ones, and $\mathrm{Mg}$ level in leaves from $0 \mathrm{mM} \mathrm{Mg-treated}$ seedlings was much less than the sufficient range (Fig. 1) [37]. Based on these data and our previous reports $[6,12]$, these seedlings submitted to 0 and $1 \mathrm{mM} \mathrm{Mg}$ were regarded as Mg-deficient and -sufficient (control), respectively.

\section{Illumina sequencing and miRNA annotation}

Using high-throughput sequencing, we got 20,726,716 $(22,139,574)$ raw reads from sRNA library constructed from control (Mg-deficient) roots. After the adaptors, low quality tags and contaminants being removed, the control and Mg-deficient root sRNA libraries generated $20,325,777(5,561,214)$ and $21,783,568(6,124,980)$ clear reads (unique reads), respectively (Table 1 ). As shown in Fig. 2, the majority of the clear reads fell within the range of 18-25 nt. The most abundant clear reads were 24 nt length, followed by 21, 22, 23 and 20 nt length. This agrees with the previous data obtained on leaves, roots [17, 18] and fruits [38] of C. sinensis, and fruits and flowers of Citrus trifoliata [39]. Therefore, these data obtained via high-throughput sequencing of sRNA libraries are reliable. Mg-deficiency increased and decreased the abundances of 24 and 21 nt reads, respectively.

Here, $13,624,836$ clean reads $(3,077,845$ unique reads) from Mg-sufficient roots and 14,510,776 clear reads (3,378,231 unique reads) from $\mathrm{Mg}$-deficient roots were mapped to $C$. sinensis genome (JGIversion1.1, http:// phytozome.jgi.doe.gov/pz/portal.html\#!info?alias=Org_C sinensis) using SOAP [40]. Thereafter, we used the unannotated 5,050,734 and 5,550,820 unique reads from Mg-sufficient and -deficient roots, respectively to predict novel miRNAs (Table 1). 


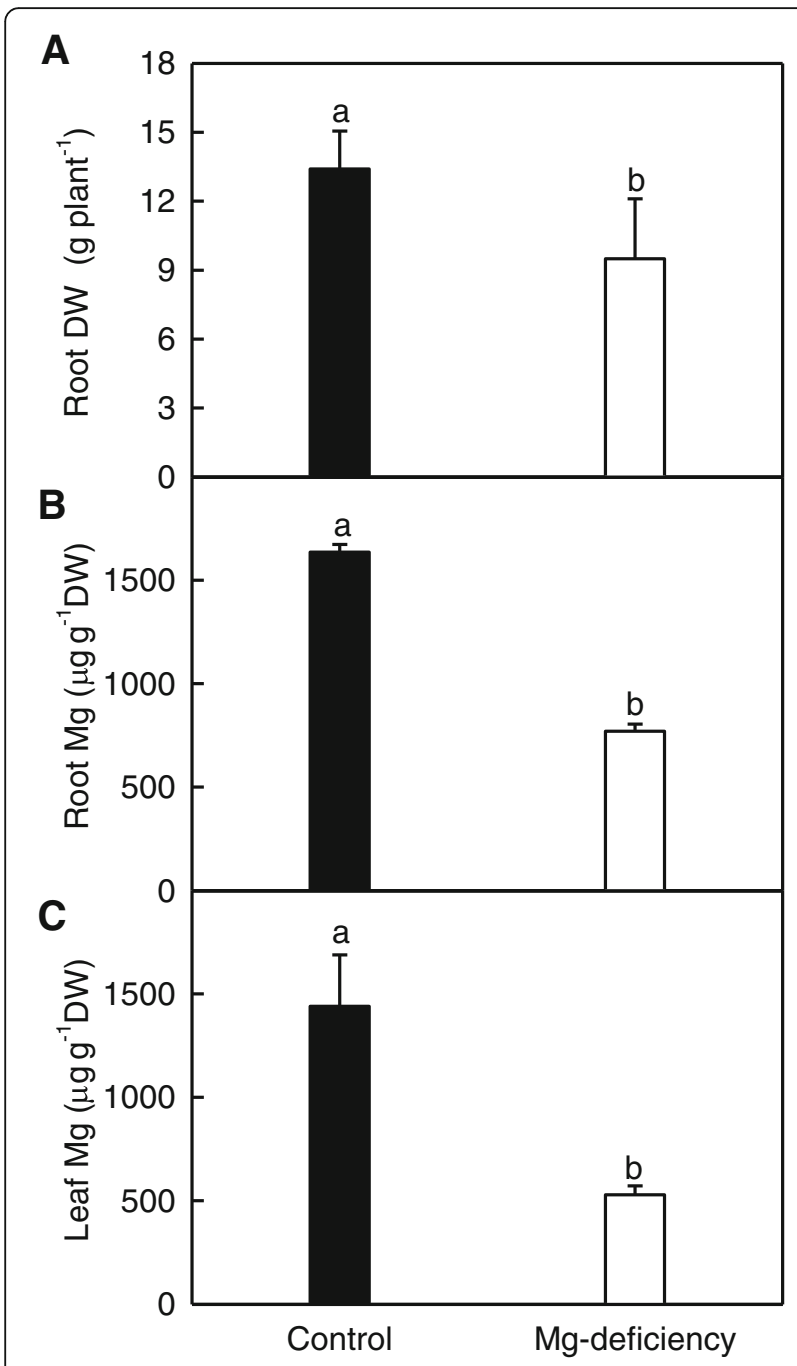

Fig. 1 Root DW (a), root (b) and leaf (c) Mg concentrations in response to Mg-deficiency. Bars represent mean \pm SD ( $n=5$ for root and leaf $\mathrm{Mg}$ and 9 for root DW). Different letters above the bars indicate a significant difference at $P<0.05$

Identification and prediction of root miRNAs

As shown in Additional file 1, we identified 733 known miRNAs in $C$. sinensis roots. To avert false results due to the use of low abundant miRNAs, these known miRNAs with a transcript per million (TPM) value $<10$ in both $\mathrm{Mg}$-sufficient and -deficient roots were not utilized for further analysis [17, 41]. The remained 300 miRNAs with a TPM value $\geq 10$ in Mg-sufficient and/or -deficient roots were utilized for Mg-deficiency-responsive miRNA analysis (Additional file 2). As shown in Additional file 3, we obtained 71 up- and 54 down-regulated known miRNAs from $\mathrm{Mg}$ deficient roots.

As shown in Additional files 4, 5, and 6, we identified 181 novel miRNAs in both Mg-sufficient and -deficient roots, and 30 up- and 15 down-regulated novel miRNAs in Mg-deficient roots with a TPM value $\geq$ ten in $\mathrm{Mg}$ deficient and/or -sufficient roots.

\section{Validation of sequencing data by stem-loop qRT-PCR}

The expression levels of $27 \mathrm{Mg}$-deficiency-responsive miRNAs were assayed by stem-loop qRT-PCR. Except for $m i R 1222$, the expression patterns of all miRNAs obtained by stem-loop qRT-PCR and Illumiona sequencing were similar (Fig. 3 and Table 2). Thus, the results produced by Illumiona sequencing were reliable.

\section{Prediction and GO analysis of targets for Mg-deficiency- responsive miRNAs}

Here, we predicted 239 and 130 target genes from the 46 known and 15 novel Mg-deficiency-responsive-miRNAs, respectively (Additional files 7 and 8). As shown in Fig. 4a, the targets for known (novel) Mg-deficiencyresponsive miRNAs were associated with 12 (nine) biological processes. The most abundant three GO terms were response to stress, transport and protein process for known miRNA targets and response to stress, regulation of transcription and transport for novel miRNA targets, respectively. On the basis of the molecular function, the highest percentages of three groups for known and novel miRNA targets were nucleic acid binding, other activity and kinase activity, and other activity, metal ion binding and transporter activity, respectively (Fig. 4b). As shown in Fig. 4c, the targets for known (novel) Mg-deficiency-responsive miRNAs were related to 12 (eight) cellular components. The most abundant component for known and novel miRNAs was nucleus.

\section{Validation of target genes by qRT-PCR}

As shown in Table 2, 105 targets for 11 up- and 16 down-regulated miRNAs were validated by qRT-PCR. As expected, we found that 65 (61.9\%) targets and their corresponding miRNAs displayed opposite trends in expression profiles in Mg-deprived roots, suggesting that miRNAs might play a role in gene regulation by cleaving mRNAs. However, 34 (32.4\%) targets displayed the same expression profiles with their corresponding miRNAs in $\mathrm{Mg}$-deficient roots or were not significantly affected by Mg-deficiency. The remaining $6(0.06 \%)$ targets were not detected in roots. It is worth mentioning that 4 target genes (i.e., range1.1g005482m, orange1.1g004896m, orange1.1g005075m and orange1.1g008078m) belonging to auxin responsive factor (ARF) family have been validated by us in $C$. sinensis [42], suggesting that the target prediction was accurate.

\section{Discussion}

Little is known about the possible roles of miRNAs in plant Mg homeostasis [36, 43]. Here, we first 
Table 1 Summary of sRNA sequencing data from Mg-sufficient and-deficient Citrus sinensis roots

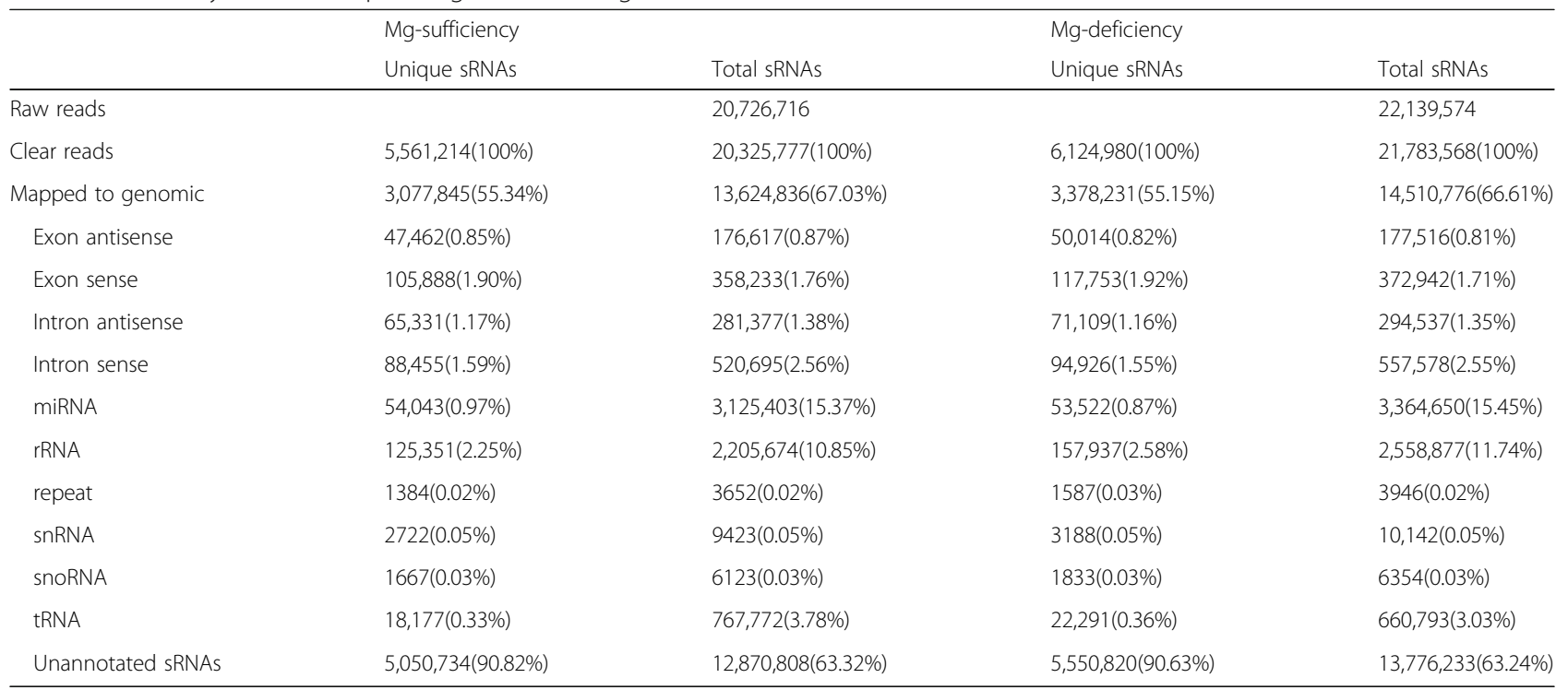

investigated the Mg-deficiency-induced alterations of miRNA profiles in Citrus roots and obtained 101 upand 69 down-regulated miRNAs (Additional files 3 and 6), demonstrating that miRNAs might be involved in Mg-deficiency responses. We obtained similar amount of miRNAs (71 miRNAs) with decreased expression, but less amount of miRNAs (75 miRNAs) with increased expression from Mg-deficient C. sinensis leaves compared with Mg-deficient $C$. sinensis roots [36]. Moreover, most of these miRNAs were isolated only from $\mathrm{Mg}$-deprived roots or leaves, only 30 Mg-deficiency-responsive miRNAs were shared by the two. Among the 30 overlapping miRNAs, only 15 miRNAs displayed similar expression trends in Mg-deprived roots and leaves (Table 3). Thus, great differences existed in $\mathrm{Mg}$-deficiencyinduced alterations of miRNA profiles between roots and leaves. This agrees with our report that the

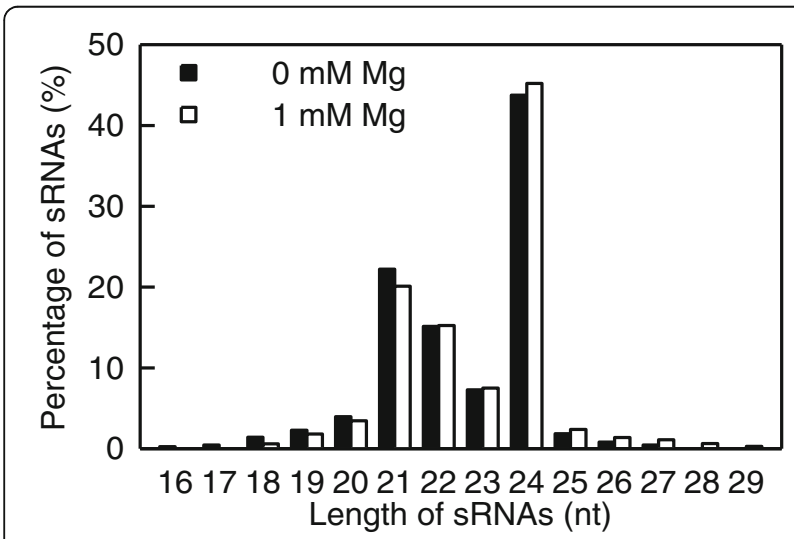

Fig. 2 Small RNA length distribution from Mg-deficient and -sufficient C. sinensis roots physiological and biochemical responses to long-term Mg-deficiency greatly differed between C. sinensis roots and leaves [7].

We observed that miR158 was induced in $\mathrm{Mg}$ deprived roots (Table 2). Similar results have been obtained on Mg-deficient C. sinensis leaves [36], Pdeficient tomato roots and leaves [22], and B-starved $C$. sinensis roots and leaves $[17,18]$. As expected, its target gene SPFH (stomatins, prohibitins, flotillins and HflK/ C)/Band 7/PHB domain-containing membraneassociated protein family (AT5G62740) was repressed in Mg-deprived roots. Wang et al. [44] found that Arabidopsis phb3-3 mutants were less sensitive to salt-stressinduced inhibition of primary root growth. Thus, the down-regulation of AT5G62740 might contribute to Citrus Mg-deficiency tolerance via alleviating $\mathrm{Mg}$ deficiency-induced inhibition of root growth (Fig. 1a). Gehl et al. [45] observed that the basal tissue respiration rate in stomatin-like protein 1 (slp1) knockout Arabidopsis roots was reduced by $30 \%$ compared with wild-type. In addition, miR2919 expression was induced and its target: phosphoenolpyruvate carboxylase 3 (PEPC3) was inhibited in Mg-deprived C. sinensis roots (Table 2). Therefore, root respiration might be decreased in Mg-starved C. sinensis roots. This agrees with our reports that the abundances of pyruvate decarboxylase (gi|255,579,310) and phosphoglycerate kinase (gi|332,195,235) in glycolysis and the activities of key enzymes in glycolysis and tricarboxylic acid (TCA) cycle were reduced in $\mathrm{Mg}$ deprived C. sinensis roots accompanied by decreased accumulation of carbohydrates and lower respiration $[7,12]$.

Both root miR6278 and its targets: NB-ARC domaincontaining disease resistance protein involved in disease resistance and DnaJ/Hsp40 cysteine-rich domain 


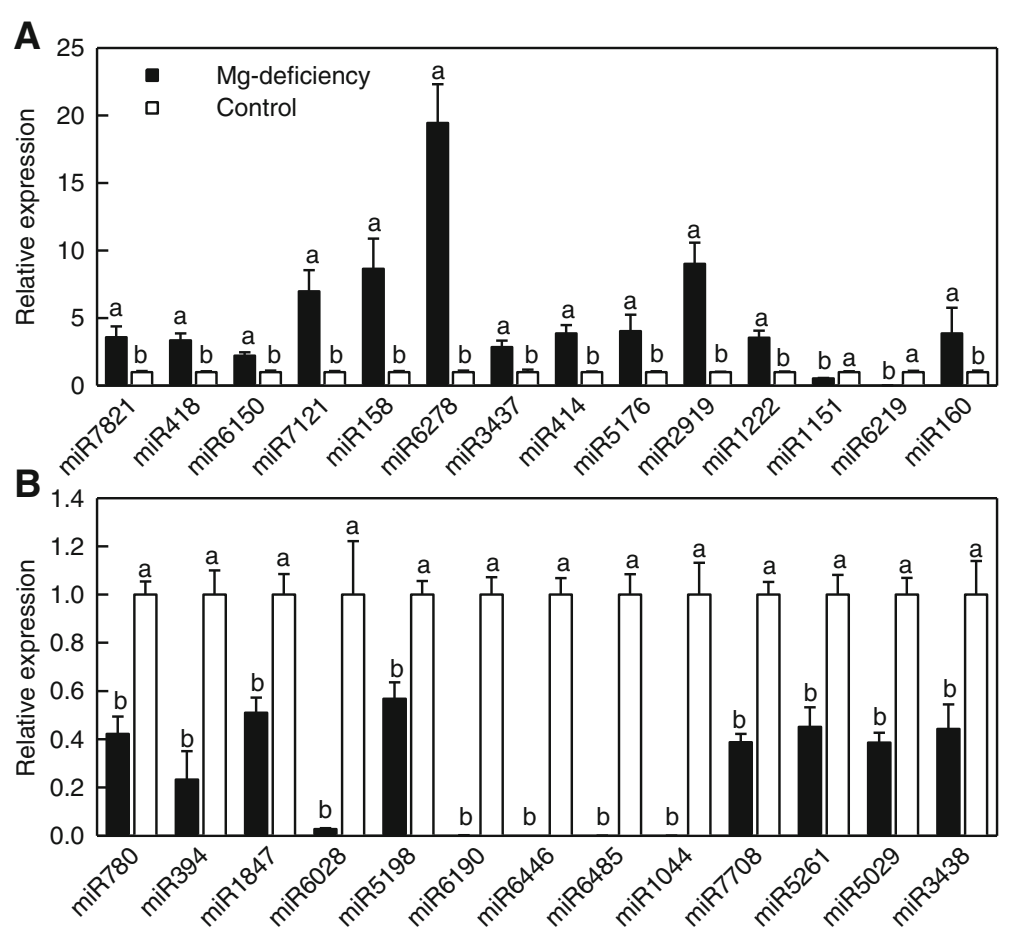

Fig. 3 Relative expression levels of selected Mg-deficiency-responsive known miRNAs in Mg-deficient and control roots revealed by qRT-PCR. Bars represent mean $\pm \mathrm{SD}(n=3)$. For the same miRNA, different letters above the bars indicate a significant difference at $P<0.05$. All the values were expressed relative to the control roots

superfamily protein (AT3G14470.1) were induced by Mgdeficiency. In addition, NB-ARC domain-containing disease resistance protein (AT4G27220.1) targeted by miR780 was induced in Mg-depprived roots (Table 2). Similarly, the abundances of Grp94 (HSP; gi|23,477,636) and disease resistance protein (gi|227,438,123) was increased in Mg-starved C. sinensis roots [12]. Thus, disease resistance might be elevated in these roots with increased levels of $\mathrm{Ca}$ and $\mathrm{K}$ [46], which contribute to plant disease resistance $[47,48]$.

MiR414 mainly targets transcriptional regulators including MYB, bZIP family transcription factors, WRKY and scarecrow and might have key roles in plant growth and development [49]. As expected, miR414 was up-regulated and its target gene: $\operatorname{poly}(A)$ polymerase 1 was inhibited in Mg-deprived roots (Table 2). This was also supported by our reports that the abundances of transcription factor homolog BTF3-like protein (gi|33,945,882), spliceosome RNA helicase BAT1 (gi|226,528,292) and RNA polymerase $\beta$ chain (gi| $90,403,817$ ) were lowered in Mg-deficient C. sinensis roots [12].

We found that miR1847 was inhibited in Mg-deprived roots (Table 2). This agrees with the results obtained on B-deficient roots [17] and disagrees with the data obtained on B-deficient leaves [18]. As expected, its target genes: ribosomal protein S3 family proteins were upregulated in these roots. In addition, VALRS targeted by
miR6485 were induced or was little affected in $\mathrm{Mg}$ starved roots (Table 2). Thus, protein biosynthesis might not be lowered in Mg-starved roots, as shown by unchanged concentration of total soluble proteins in Mg-deprived C. sinensis roots [7, 12]. Also, the reduced dilution due to the decrease in root DW (Fig. 1a) might account for the unchanged protein level.

MiR5176 was induced in Mg-deprived roots (Table 2), as found on B-starved C. sinensis roots [17]. DNA mismatch repair (MMR) system is required for the correction of DNA biosynthetic errors [50]. MUTL-homologue 1 (MLH1) participates in DNA MMR, correcting DNA damage and insertion-deletion loops arising from DNA replication [51]. MLH1 targeted by miR5176 were induced rather than inhibited in Mg-deprived roots (Table 2). Thus, MMR system might be up-regulated in these roots, thus enhancing Citrus Mg-deficiency tolerance via correcting DNA biosynthetic errors. Similarly, DNA repair and meiosis protein (Mre11) targeted by miR5261 was induced in Mg-deprived roots (Table 2).

Plant leucine-rich repeat receptor-like kinase proteins play crucial roles in abiotic stresses [52]. MiR5198 and its target gene: leucine-rich receptor-like protein kinase $(L R-R L K)$ family protein were repressed and induced in Mg-starved roots, respectively (Table 2). Similarly, leucine-rich repeat receptor-like protein kinase (ACN59310.1) was up-regulated in Mg-starved C. 
Table 2 qRT-PCR analysis of predicted target genes for selected Mg-deficiency-responsive known miRNAs in C. sinensis roots

\begin{tabular}{|c|c|c|c|c|c|c|}
\hline miRNA & $\begin{array}{l}\text { Fold change } \\
\text { of miRNA }\end{array}$ & Accession & Homology & Target genes & Potential roles & $\begin{array}{l}\text { Relative } \\
\text { change of } \\
\text { target genes }\end{array}$ \\
\hline miR158 & $9.23711361^{* *}$ & orange1.1g022993m & AT5G62740.1 & $\begin{array}{l}\text { SPFH/Band 7/PHB domain-containing } \\
\text { membrane-associated protein family }\end{array}$ & Stress response & $0.73^{* *}$ \\
\hline miR1222 & $-13.23073355^{* *}$ & orange1.1g037429m & AT4G27220.1 & $\begin{array}{l}\text { NB-ARC domain-containing disease } \\
\text { resistance protein }\end{array}$ & $\begin{array}{l}\text { Disease resistance } \\
\text { protein }\end{array}$ & ND \\
\hline miR2919 & $6.01101607^{* *}$ & orange $1.1 \mathrm{~g} 002089 \mathrm{~m}$ & AT3G14940.1 & Phosphoenolpyruvate carboxylase 3 & $\begin{array}{l}\text { Carbohydrate } \\
\text { metabolism }\end{array}$ & $0.53^{* *}$ \\
\hline miR3437 & $3.97352136^{* *}$ & orange1.1g040557m & AT1G56140.1 & $\begin{array}{l}\text { Leucine-rich repeat transmembrane } \\
\text { protein kinase }\end{array}$ & $\begin{array}{l}\text { Transmembrane } \\
\text { signal transduction }\end{array}$ & $0.65 * *$ \\
\hline miR7821 & $4.13197145^{* *}$ & orange1.1g010745m & AT1G29760.1 & $\begin{array}{l}\text { Putative adipose-regulatory } \\
\text { protein (Seipin) }\end{array}$ & $\begin{array}{l}\text { Triacylglycerol } \\
\text { accumulation and } \\
\text { LD proliferation }\end{array}$ & 0.95 \\
\hline miR394 & $-5.44692358^{* *}$ & orange1.1g000114m & AT1G20960.1 & $\begin{array}{l}\text { U5 small nuclear ribonucleoprotein } \\
\text { helicase, putative }\end{array}$ & mRNA processing & 1.48 \\
\hline \multirow[t]{2}{*}{ miR414 } & $3.01957377^{* *}$ & orange1.1g004767m & AT1G17980.1 & Poly(A) polymerase 1 & mRNA processing & 0.76 \\
\hline & & orange1.1g006232m & AT1G17980.1 & Poly(A) polymerase 1 & mRNA processing & $0.72^{* *}$ \\
\hline miR418 & $2.16768709^{* *}$ & orange1.1g003146m & AT1G20780.1 & $\begin{array}{l}\text { Senescence-associated } \\
\text { E3 ubiquitin ligase } 1\end{array}$ & $\begin{array}{l}\text { Ubl conjugation } \\
\text { pathway }\end{array}$ & 0.78 \\
\hline \multirow[t]{3}{*}{ miR6150 } & $8.95879131^{* *}$ & orange1.1g009434m & AT5G62810.1 & Peroxin 14 & $\begin{array}{l}\text { Protein import into } \\
\text { peroxisome matrix, } \\
\text { docking }\end{array}$ & $3.91^{* *}$ \\
\hline & & orange1.1g009573m & AT5G62810.1 & Peroxin 14 & $\begin{array}{l}\text { Protein import into } \\
\text { peroxisome matrix, } \\
\text { docking }\end{array}$ & $2.36^{*}$ \\
\hline & & orange1.1g018459m & AT3G28715.1 & $\begin{array}{l}\text { ATPase, V0/A0 complex, } \\
\text { subunit C/D }\end{array}$ & $\begin{array}{l}\text { ATP hydrolysis coupled } \\
\text { proton transport }\end{array}$ & 0.82 \\
\hline \multirow[t]{2}{*}{ miR6278 } & $8.85634619^{* *}$ & orange1.1g005896m & AT3G14470.1 & $\begin{array}{l}\text { NB-ARC domain-containing } \\
\text { disease resistance protein }\end{array}$ & $\begin{array}{l}\text { Disease resistance } \\
\text { protein }\end{array}$ & $1.63^{* *}$ \\
\hline & & orange1.1g030696m & AT5G17840.1 & $\begin{array}{l}\text { DnaJ/Hsp40 cysteine-rich domain } \\
\text { superfamily protein }\end{array}$ & Stress response & $1.56^{* *}$ \\
\hline \multirow[t]{3}{*}{ miR1847 } & $-2.21361107^{* *}$ & orange $1.1 \mathrm{~g} 026316 \mathrm{~m}$ & AT5G35530.1 & Ribosomal protein S3 family protein & Translation & $2.76^{* *}$ \\
\hline & & orange $1.1 \mathrm{~g} 026835 \mathrm{~m}$ & AT5G35530.1 & Ribosomal protein $\mathrm{S} 3$ family protein & Translation & $1.84^{*}$ \\
\hline & & orange1.1g029201m & AT2G31610.1 & Ribosomal protein $\$ 3$ family protein & Translation & 1.91 \\
\hline \multirow[t]{9}{*}{ miR6028 } & $-2.29912898^{* *}$ & orange1.1g005923m & AT2G33580.1 & LysM-containing receptor-like kinase 5 & $\begin{array}{l}\text { Transmembrane } \\
\text { signal transduction }\end{array}$ & $0.67^{* *}$ \\
\hline & & orange1.1g034040m & AT5G42990.1 & Ubiquitin-conjugating enzyme 18 & Protein ubiquitination & ND \\
\hline & & orange1.1g021729m & AT4G29100.1 & $\begin{array}{l}\text { Basic helix-loop-helix (bHLH) } \\
\text { DNA-binding superfamily protein }\end{array}$ & Transcription factor & ND \\
\hline & & orange1.1g026539m & AT1G79020.1 & $\begin{array}{l}\text { Enhancer of polycomb-like } \\
\text { transcription factor protein }\end{array}$ & Transcription regulation & ND \\
\hline & & orange1.1g045123m & AT4G35800.1 & RNA polymerase II large subunit & mRNA synthesis & ND \\
\hline & & orange1.1g003175m & AT4G14700.1 & Origin recognition complex 1 & $\begin{array}{l}\text { DNA synthesis } \\
\text { and replication }\end{array}$ & $0.57^{* *}$ \\
\hline & & orange $1.1 \mathrm{~g} 006076 \mathrm{~m}$ & АT3G46790.1 & $\begin{array}{l}\text { Tetratricopeptide repeat } \\
\text { (TPR)-like superfamily protein }\end{array}$ & & $6.01 * *$ \\
\hline & & orange1.1g029970m & АT3G49940.1 & LOB domain-containing protein 38 & & $6.05^{* *}$ \\
\hline & & orange1.1g028357m & АT2G45850.2 & $\begin{array}{l}\text { AT-hook motif nuclear-localized } \\
\text { protein } 9 \text { (AHL9) }\end{array}$ & Transcription factor & $6.12^{* *}$ \\
\hline \multirow[t]{4}{*}{ miR5176 } & $4.58746604^{* *}$ & orange1.1g005789m & AT4G09140.1 & MUTL-homologue 1 & DNA mismatch repair & $3.21^{* *}$ \\
\hline & & orange1.1g008397m & AT4G09140.1 & MUTL-homologue 1 & DNA mismatch repair & $2.87^{* *}$ \\
\hline & & orange1.1g010846m & AT4G09140.1 & MUTL-homologue 1 & DNA mismatch repair & $3.13^{* *}$ \\
\hline & & orange1.1g012406m & AT4G09140.1 & MUTL-homologue 1 & DNA mismatch repair & $5.39^{*}$ \\
\hline
\end{tabular}


Table 2 qRT-PCR analysis of predicted target genes for selected Mg-deficiency-responsive known miRNAs in C. sinensis roots (Continued)

\begin{tabular}{|c|c|c|c|c|c|c|}
\hline \multirow[t]{8}{*}{ miR7121 } & $4.74373348^{* *}$ & orange1.1g005267m & AT1G71400.1 & Receptor like protein 12 & $\begin{array}{l}\text { Hormone-mediated } \\
\text { signaling pathway }\end{array}$ & $0.66 * *$ \\
\hline & & orange1.1g005542m & AT1G71400.1 & Receptor like protein 12 & $\begin{array}{l}\text { Hormone-mediated } \\
\text { signaling pathway }\end{array}$ & $0.77^{* *}$ \\
\hline & & orange1.1g008628m & AT1G71400.1 & Receptor like protein 12 & $\begin{array}{l}\text { Hormone-mediated signaling } \\
\text { pathway }\end{array}$ & $1.76^{* *}$ \\
\hline & & orange1.1g002167m & AT5G27060.1 & Receptor like protein 53 & $\begin{array}{l}\text { Hormone-mediated signaling } \\
\text { pathway }\end{array}$ & $5.01^{* *}$ \\
\hline & & orange1.1g012980m & AT5G53390.1 & O-acyltransferase (WSD1-like) family protein & $\begin{array}{l}\text { Lipid and fatty-acid } \\
\text { metabolism }\end{array}$ & 0.86 \\
\hline & & orange1.1g013532m & AT5G53390.1 & O-acyltransferase (WSD1-like) family protein & $\begin{array}{l}\text { Lipid and fatty-acid } \\
\text { metabolism }\end{array}$ & $0.72^{* *}$ \\
\hline & & orange1.1g027358m & AT5G03080.1 & $\begin{array}{l}\text { Phosphatidic acid phosphatase (PAP2) } \\
\text { family protein }\end{array}$ & Dephosphorylation & $0.53^{* *}$ \\
\hline & & orange1.1g027353m & AT5G03080.1 & $\begin{array}{l}\text { Phosphatidic acid phosphatase (PAP2) } \\
\text { family protein }\end{array}$ & Dephosphorylation & $0.56^{* *}$ \\
\hline \multirow[t]{3}{*}{ miR6190 } & $-3.61190068^{* *}$ & orange1.1g029300m & AT5G64200.1 & Ortholog of human splicing factor SC35 & SR protein & $2.65^{* *}$ \\
\hline & & orange1.1g017284m & AT5G34850.1 & Purple acid phosphatase 26 & $\begin{array}{l}\text { Phosphate ion } \\
\text { homeostasis }\end{array}$ & $1.82^{* *}$ \\
\hline & & orange1.1g002842m & AT4G01810.1 & $\begin{array}{l}\text { Sec } 23 / \text { Sec } 24 \text { protein transport family } \\
\text { protein }\end{array}$ & $\begin{array}{l}\text { Intracellular } \\
\text { protein transport }\end{array}$ & $1.64^{* *}$ \\
\hline \multirow[t]{4}{*}{ miR6446 } & $-3.77151631^{* *}$ & orange1.1g016909m & AT5G09300.1 & $\begin{array}{l}\text { Thiamin diphosphate-binding fold } \\
\text { (THDP-binding) superfamily protein }\end{array}$ & $\begin{array}{l}\text { Lipid and fatty-acid } \\
\text { metabolism }\end{array}$ & $3.23^{* *}$ \\
\hline & & orange1.1g023827m & AT5G09300.1 & $\begin{array}{l}\text { Thiamin diphosphate-binding fold } \\
\text { (THDP-binding) superfamily protein }\end{array}$ & $\begin{array}{l}\text { Lipid and fatty-acid } \\
\text { metabolism }\end{array}$ & $2.56 * *$ \\
\hline & & orange1.1g001557m & AT5G20280.1 & Sucrose phosphate synthase $1 \mathrm{~F}$ & $\begin{array}{l}\text { C-compound and } \\
\text { carbohydrate metabolism }\end{array}$ & $3.51^{* *}$ \\
\hline & & orange1.1g002665m & AT5G20280.1 & Sucrose phosphate synthase $1 \mathrm{~F}$ & $\begin{array}{l}\text { C-compound and } \\
\text { carbohydrate metabolism }\end{array}$ & $3.93^{* *}$ \\
\hline \multirow[t]{16}{*}{ miR6485 } & $-4.69704327^{* *}$ & orange1.1g001969m & AT5G20730.2 & $\begin{array}{l}\text { Transcriptional factor B3 family protein / } \\
\text { auxin-responsive factor AUX/IAA-related }\end{array}$ & Transcription factor & $1.41^{*}$ \\
\hline & & orange1.1g011274m & AT3G22810.1 & $\begin{array}{l}\text { Plant protein of unknown function (DUF828) } \\
\text { with plant pleckstrin homology-like region }\end{array}$ & & $1.68^{* *}$ \\
\hline & & orange1.1g031218m & AT1G07400.1 & HSP20-like chaperones superfamily protein & Stress response & 0.88 \\
\hline & & orange1.1g009779m & AT1G08960.1 & Cation exchanger 11 & Transport & $0.57^{* *}$ \\
\hline & & orange1.1g029454m & AT5G51160.1 & Ankyrin repeat family protein & & $0.20^{* *}$ \\
\hline & & orange1.1g013633m & AT1G28560.1 & SnRNA activating complex family protein & Auxin signaling pathway & $2.27^{* *}$ \\
\hline & & orange1.1g017698m & AT1G28560.1 & SnRNA activating complex family protein & Auxin signaling pathway & $1.33^{* *}$ \\
\hline & & orange1.1g042988m & AT5G62850.1 & Nodulin MtN3 family protein & Transport & $0.59^{* *}$ \\
\hline & & orange1.1g007868m & AT1G72650.2 & Myb family transcription factor TRFL6 & Transcription factor & $4.39 * *$ \\
\hline & & orange1.1g046667m & AT2G38940.1 & Phosphate transporter $1 ; 4$ & Phosphate transport & 0.91 \\
\hline & & orange1.1g001289m & AT1G14610.1 & $\begin{array}{l}\text { Valyl-tRNA synthetase / valine-tRNA } \\
\text { ligase (VALRS) }\end{array}$ & Protein biosynthesis & $1.75^{* *}$ \\
\hline & & orange1.1g001303m & AT1G14610.1 & $\begin{array}{l}\text { Valyl-tRNA synthetase / valine-tRNA } \\
\text { ligase (VALRS) }\end{array}$ & Protein biosynthesis & $1.99 * *$ \\
\hline & & orange1.1g001757m & AT1G14610.1 & $\begin{array}{l}\text { Valyl-tRNA synthetase / valine-tRNA } \\
\text { ligase (VALRS) }\end{array}$ & Protein biosynthesis & 1.11 \\
\hline & & orange1.1g024117m & AT2G47920.1 & Kinase interacting (KIP1-like) family protein & & $0.21^{* *}$ \\
\hline & & orange1.1g036588m & AT4G20140.1 & $\begin{array}{l}\text { Leucine-rich repeat transmembrane } \\
\text { protein kinase }\end{array}$ & $\begin{array}{l}\text { Transmembrane } \\
\text { signal transduction }\end{array}$ & $4.54^{*}$ \\
\hline & & orange1.1g003591m & AT5G05680.1 & Nuclear pore complex protein NUP88 & $\begin{array}{l}\text { mRNA transport, } \\
\text { protein transport }\end{array}$ & $1.59^{*}$ \\
\hline
\end{tabular}


Table 2 qRT-PCR analysis of predicted target genes for selected Mg-deficiency-responsive known miRNAs in C. sinensis roots (Continued)

\begin{tabular}{|c|c|c|c|c|c|c|}
\hline \multirow[t]{5}{*}{ miR1044 } & \multirow[t]{5}{*}{$-5.19771615^{* *}$} & orange1.1g001378m & AT1G10170.1 & NF-X-like 1 & Protein ubiquitination & $2.00^{* *}$ \\
\hline & & orange1.1g001376m & AT1G10170.1 & NF-X-like 1 & Protein ubiquitination & $2.61^{*}$ \\
\hline & & orange1.1g047796m & AT2G38380.1 & Peroxidase superfamily protein & Stress response & $1.97^{* *}$ \\
\hline & & orange1.1g042193m & AT5G03340.1 & ATPase, AAA-type, CDC48 protein & $\begin{array}{l}\text { Cell cycle, cell division, } \\
\text { protein transport, } \\
\text { transport }\end{array}$ & $4.02^{*}$ \\
\hline & & orange $1.1 \mathrm{~g} 019546 \mathrm{~m}$ & AT2G40340.1 & $\begin{array}{l}\text { Integrase-type DNA-binding } \\
\text { superfamily protein }\end{array}$ & $\begin{array}{l}\text { Abscisic acid signaling } \\
\text { pathway }\end{array}$ & $0.60^{* *}$ \\
\hline miR5198 & $-5.36879795^{* *}$ & orange1.1g002063m & AT1G72180.1 & $\begin{array}{l}\text { Leucine-rich receptor-like protein } \\
\text { kinase family protein }\end{array}$ & $\begin{array}{l}\text { Transmembrane signal } \\
\text { transduction }\end{array}$ & $1.84^{* *}$ \\
\hline \multirow[t]{6}{*}{ miR5029 } & \multirow[t]{6}{*}{$-5.99278869^{* *}$} & orange1.1g012168m & AT5G53450.1 & OBP3-responsive gene 1 & & $0.03^{* *}$ \\
\hline & & orange $1.1 \mathrm{~g} 026587 \mathrm{~m}$ & AT4G31300.3 & Proteasome subunit beta type- 6 (PBA1) & Protein ubiquitination & $2.26^{* *}$ \\
\hline & & orange1.1g029964m & AT4G31300.3 & Proteasome subunit beta type- 6 (PBA1) & Protein ubiquitination & $2.21^{* *}$ \\
\hline & & orange1.1g030788m & AT4G31300.3 & Proteasome subunit beta type- 6 (PBA1) & Protein ubiquitination & $2.91^{* *}$ \\
\hline & & orange1.1g014625m & AT3G23510.1 & $\begin{array}{l}\text { Cyclopropane-fatty-acyl-phospholipid } \\
\text { synthase }\end{array}$ & $\begin{array}{l}\text { Lipid and fatty-acid } \\
\text { metabolism }\end{array}$ & $2.44^{* *}$ \\
\hline & & orange1.1g018123m & АT3G44160.1 & Outer membrane OMP85 family protein & Transmembrane transport & $1.43^{*}$ \\
\hline \multirow[t]{14}{*}{ miR5261 } & \multirow[t]{14}{*}{$-6.08070339 * *$} & orange1.1g018132m & AT3G56930.1 & DHHC-type zinc finger family protein & & $1.94^{* *}$ \\
\hline & & orange1.1g010695m & AT3G12640.1 & $\begin{array}{l}\text { RNA binding (RRM/RBD/RNP motifs) } \\
\text { family protein }\end{array}$ & mRNA processing & $2.40^{* *}$ \\
\hline & & orange1.1g011967m & AT3G12640.1 & $\begin{array}{l}\text { RNA binding (RRM/RBD/RNP motifs) } \\
\text { family protein }\end{array}$ & mRNA processing & $2.80^{* *}$ \\
\hline & & orange1.1g031636m & AT1G67620.1 & Lojap-related protein & & $2.41^{* *}$ \\
\hline & & orange $1.1 \mathrm{~g} 033883 \mathrm{~m}$ & AT1G67620.1 & Lojap-related protein & & $2.03 * *$ \\
\hline & & orange1.1g004959m & AT5G66850.1 & $\begin{array}{l}\text { Mitogen-activated protein kinase kinase } \\
\text { kinase } 5\end{array}$ & Intracellular signalling & $1.97^{*}$ \\
\hline & & orange $1.1 \mathrm{~g} 043928 \mathrm{~m}$ & AT2G36110.1 & $\begin{array}{l}\text { Polynucleotidyl transferase, ribonuclease } \\
\text { H-like superfamily protein }\end{array}$ & $3^{\prime}-5$ ' exonuclease activity & $3.32^{* *}$ \\
\hline & & orange $1.1 \mathrm{~g} 037980 \mathrm{~m}$ & AT2G36110.1 & $\begin{array}{l}\text { Polynucleotidyl transferase, ribonuclease } \\
\text { H-like superfamily protein }\end{array}$ & 3'-5' exonuclease activity & $2.17^{* *}$ \\
\hline & & orange1.1g004713m & AT5G54260.1 & DNA repair and meiosis protein (Mre11) & $\begin{array}{l}\text { DNA damage, } \\
\text { DNA repair, meiosis }\end{array}$ & $4.47^{* *}$ \\
\hline & & orange1.1g010785m & AT3G26020.2 & $\begin{array}{l}\text { Protein phosphatase } 2 \mathrm{~A} \text { regulatory } \\
\text { B subunit family protein }\end{array}$ & Intracellular signalling & $2.01^{*}$ \\
\hline & & orange1.1g000012m & AT1G55860.2 & $\begin{array}{l}\text { Ubiquitin-protein ligase } 1 \\
\text { (E3 ubiquitin-protein ligase UPL1) }\end{array}$ & Protein ubiquitination & $2.05^{* *}$ \\
\hline & & orange $1.1 \mathrm{~g} 000013 \mathrm{~m}$ & AT1G55860.2 & $\begin{array}{l}\text { Ubiquitin-protein ligase } 1 \\
\text { (E3 ubiquitin-protein ligase UPL1) }\end{array}$ & Protein ubiquitination & $2.82^{* *}$ \\
\hline & & orange1.1g029528m & AT5G01520.1 & RING/U-box superfamily protein & Protein ubiquitination & $4.05^{*}$ \\
\hline & & orange1.1g029508m & AT1G22360.1 & UDP-glucosyl transferase $85 \mathrm{~A} 2$ & $\begin{array}{l}\text { Flavonoid biosynthetic } \\
\text { process }\end{array}$ & $1.99 * *$ \\
\hline miR3438 & $-9.31063262^{* *}$ & orange $1.1 \mathrm{~g} 000163 \mathrm{~m}$ & AT1G55325.2 & RNA polymerase II transcription mediators & & 2.29 \\
\hline \multirow[t]{8}{*}{ miR1151 } & \multirow[t]{8}{*}{$-10.44661802^{* *}$} & orange1.1g018149m & AT5G49610.1 & F-box family protein & Protein ubiquitination & $1.82^{*}$ \\
\hline & & orange1.1g018125m & AT5G49610.1 & F-box family protein & Protein ubiquitination & 2.69* \\
\hline & & orange1.1g023739m & AT2G41870.1 & Remorin family protein & & $4.00^{* *}$ \\
\hline & & orange $1.1 \mathrm{~g} 027436 \mathrm{~m}$ & AT2G41870.1 & Remorin family protein & & $2.11^{* *}$ \\
\hline & & orange $1.1 \mathrm{~g} 023033 \mathrm{~m}$ & AT2G36690.1 & $\begin{array}{l}\text { 2-oxoglutarate (2OG) and } \\
\text { Fe(II)-dependent oxygenase } \\
\text { superfamily protein }\end{array}$ & Oxidoreductase & $2.03^{*}$ \\
\hline & & orange $1.1 \mathrm{~g} 026453 \mathrm{~m}$ & AT1G17020.1 & Senescence-related gene 1 & Oxidoreductase & $2.31^{* *}$ \\
\hline & & orange $1.1 \mathrm{~g} 020233 \mathrm{~m}$ & AT2G36690.1 & $\begin{array}{l}\text { 2-oxoglutarate (2OG) and } \\
\text { Fe(II)-dependent oxygenase } \\
\text { superfamily protein }\end{array}$ & & $3.73^{*}$ \\
\hline & & orange1.1g037473m & AT5G07480.1 & KAR-UP oxidoreductase 1 & Oxidoreductase & 1.92 \\
\hline
\end{tabular}


Table 2 qRT-PCR analysis of predicted target genes for selected Mg-deficiency-responsive known miRNAs in C. sinensis roots (Continued)

\begin{tabular}{|c|c|c|c|c|c|c|}
\hline miR6219 & $-11.91465055^{* *}$ & orange1.1g010903m & AT5G15130.1 & WRKY DNA-binding protein 72 & Transcription factor & $1.65^{* *}$ \\
\hline miR7708 & $-8.18079862^{* *}$ & orange $1.1 \mathrm{~g} 023136 \mathrm{~m}$ & AT1G06890.1 & $\begin{array}{l}\text { Nodulin MtN21 /EamA-like } \\
\text { transporter family protein }\end{array}$ & & $2.14^{* *}$ \\
\hline \multirow[t]{3}{*}{$\operatorname{miR780}$} & $-12.80878923^{* *}$ & orange $1.1 \mathrm{~g} 044623 \mathrm{~m}$ & AT5G17230.2 & Phytoene synthase & Carotenoid biosynthesis & $2.15^{*}$ \\
\hline & & orange1.1g030826m & AT2G26560.1 & Phospholipase A 2A & Lipid degradation & ND \\
\hline & & orange1.1g004573m & AT4G27220.1 & $\begin{array}{l}\text { NB-ARC domain-containing } \\
\text { disease resistance protein }\end{array}$ & Disease resistance & $1.58^{* *}$ \\
\hline \multirow[t]{4}{*}{$\operatorname{miR} 160$} & $10.33203655^{* *}$ & orange1.1g005482m & AT4G30080.1 & Auxin response factor 16 & Auxin signaling pathway & $4.54^{*}$ \\
\hline & & orange1.1g004896m & AT2G28350.1 & Auxin response factor 10 & Auxin signaling pathway & $22.94^{* *}$ \\
\hline & & orange1.1g005075m & AT4G30080.1 & Auxin response factor 16 & Auxin signaling pathway & $4.01^{* *}$ \\
\hline & & orange1.1g008078m & AT1G77850.1 & Auxin response factor 17 & Auxin signaling pathway & $2.90^{*}$ \\
\hline
\end{tabular}

The relative changes of target genes are the ratio of $\mathrm{Mg}$-deficient to -sufficient roots. The value for relative change of target gene was a mean of three biological replicates with two technical replicates; Target genes that had the expected changes in mRNA levels were marked in bold; * and ** indicate a significant difference at $P<0.05$ and $P<0.01$, respectively. ND, not detected

reticulata roots [13]. Thus, miR5198 might be involved in Citrus Mg-deficiency responses.

Root miR780 was repressed by Mg-deficiency (Table 2), as found on B-starved C. sinensis roots [17]. As expected, its targets: $N B-A R C$ domain-containing disease resistance protein and phytoene synthase (PSY) were up-regulated in Mg-starved roots (Table 2). Various transgenic plants over-expressing bacterial or plant gene encoding PSY, a major rate-limiting carotenoid (Car) enzyme, displayed increased Car level [53, 54]. Therefore, Car biosynthesis might be enhanced in Mg-starved C. sinensis roots, thus increasing their antioxidant ability.

We observed that miR7121 and its target gene: phosphatidic acid phosphatase (PAP2) family protein was up- and down-regulated in Mg-starved roots, respectively (Table 2). Nakano et al. [55] demonstrated that the inhibition of PAP2 expression or function conferred resistance to Ralstonia solanacearum via rapidly triggering plant defenses in Nicotiana benthamiana. Thus, the down-regulation of PAP2 family protein might contribute to plant diseaseresistance.

As shown in Table 2, miR6190 was down-regulated and its target genes [i.e., purple acid phosphatase 26 (PPAP26), Sec23/Sec24 protein transport family protein and ortholog of human splicing factor SC35, also known as serine/arginine-rich (SR) splicing factor SC35] were up-regulated in Mg-deficient roots. SR proteins are required for regulating alternative splicing. In higher plants, great alterations in alternative splicing due to various abiotic stresses demonstrate the roles of SR proteins in the adaptation to environmental stress [56]. Induction of acid phosphatases (APases) by P-starvation is a well-documented mechanism of plant P-deficiency tolerance. Hurley et al. [57] demonstrated that AtPPAP26 was the major contributor to P-deficiencyinducible APase activity. In addition, AtPPAP26 also showed alkaline peroxidase (POD) activity. Mg-deficiencyinduced up-regulation of root PPAP26 (Table 2) agrees with the report that AtPPAP26 was induced in P-deficient Arabidopsis roots, shoots and suspension cells [58] because $C$. sinensis leaf, stem and root P levels were reduced by Mg-deficiency [46]. Coat protein complex II (COPII) vesicles play an essential role for the export of secretory cargo from the endoplasmic reticulum (ER) to the Golgi complex in all eukaryotes [59]. Mg-deficiency-induced upregulation of root gene encoding Sec23/Sec24 protein transport family protein (Table 2), a subset of the COPII components, agrees with our report that the abundance of Sec23/Sec24 protein transport family protein was elevated in B-deficient roots [60].

In Arabidopsis, miRNA160 negatively regulates the repressor auxin response factor (ARF) family: ARF17 [61], ARF16 [62] and ARF10 [63]. The repression of these genes by miR160 is required for seed germination and the normal development of roots, stems and leaves. Li et al. [64] demonstrated that soybean miR160a negatively regulated the progress of leaf senescence via repressing its targets: ARF10, ARF16 and ARF17. We found that miR160 was induced in Mg-deficient roots (Table 2), as obtained on P-starved Lupinus albus roots [65] and N-deficient maize roots [66]. Therefore, the induction of root miR160 by Mg-deprivation might be an adaptive response. Unexpectedly, its targets: ARF10, $A R F 16$ and ARF17 were up-regulated in Mg-deprived $C$. sinensis roots (Table 2). Endogenous target mimics (eTMs) can impede the interaction between miRNAs and their authentic targets via binding to miRNAs [67, 68]. Lin et al. [69] demonstrated that eTMs repressed miR160-mediated cleavage of ARF10, ARF16 and ARF17 during longan somatic embryogenesis. No negative correlations were observed among the levels of miR160 and ARF10, ARF16 and ARF17 transcripts in longan vegetative and generative tissues. Thus, the correlations 

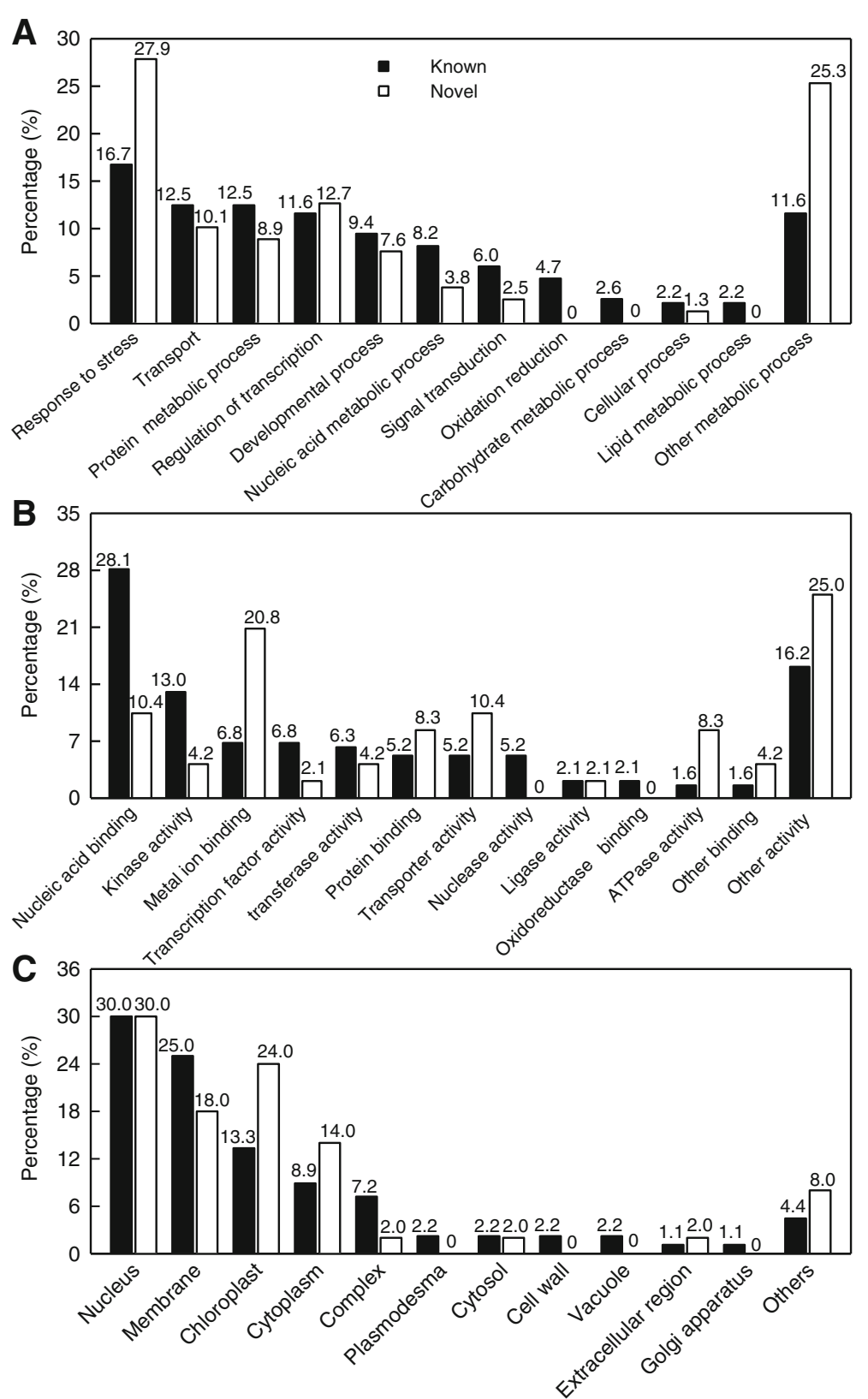

Fig. $4 \mathrm{GO}$ categories of the predicted target genes for 46 (15) Mg-deficiency-responsive known (novel) miRNAs in Citrus sinensis roots. MiRNAs target genes were grouped based on biological process (a), molecular function (b) and cellular component (c)

between miR160 and its targets in C. sinensis roots can be explained in this way.

Root miR6485 was repressed and its several target genes were up-regulated by Mg-deprivation (Table 2). Li et al. [70] reported that ARF7 (AT5G20730) is necessary for both auxin signaling and ethylene responses in Arabidopsis roots. Okushima et al. [71] observed that lateral root formation was badly damaged in Arabidopsis arf7 arf19 double knockout mutant, concluding that ARFs directly activated LATERAL ORGAN BOUNDARIES DOMAIN/ASYMMETRIC LEAVES2-LIKE (LBD/
ASL) genes, thus regulating lateral root formation. Thus, the induction of root transcriptional factor B3 family protein/auxin-responsive factor AUX/IAA-related by Mgdeficiency might play a part in Mg-deficiency tolerance via maintaining lateral root formation. Similarly, SnRNA activating complex family protein (SDR2), which is associated with auxin-activated signaling pathway, was induced in Mg-deprived roots (Table 2). Ohtani et al. [72] reported that $s r d 2$ mutation repressed the expression of PIN-FORMED proteins, which might account for the failure to generate an auxin gradient, thus leading 
Table 3 List of Mg-deficiency-responsive known miRNAs shared by both $C$. sinensis roots and leaves

\begin{tabular}{|c|c|c|}
\hline \multirow[t]{2}{*}{ MiRNA } & \multicolumn{2}{|l|}{ Fold change } \\
\hline & Leaves & Roots \\
\hline miR6108 & $-10.67424131^{* *}$ & $13.767751^{* *}$ \\
\hline miR1851 & $12.01270484^{* *}$ & $11.47852696^{* *}$ \\
\hline miR917 & $11.96734516^{* *}$ & $11.42532082^{* *}$ \\
\hline miR5525 & $-10.87750643^{* *}$ & $10.81431809^{* *}$ \\
\hline $\operatorname{miR} 158$ & $-6.05735341^{* *}$ & $9.23711361^{* *}$ \\
\hline miR1077 & $11.84568538^{* *}$ & $8.75152564^{* *}$ \\
\hline $\operatorname{miR779}$ & $-8.10749886^{* *}$ & $8.40390779^{* *}$ \\
\hline miR1168 & $6.26630003^{* *}$ & $7.67556689^{* *}$ \\
\hline miR7730 & $12.71420043^{* *}$ & $7.66997733^{* *}$ \\
\hline miR1512 & $4.98806257^{* *}$ & $7.2149053^{* *}$ \\
\hline miR1440 & $5.4977661^{* *}$ & $6.69472111^{* *}$ \\
\hline miR5782 & $-10.28908522^{* *}$ & $5.9080234^{* *}$ \\
\hline miR3520 & $4.1203203^{* *}$ & $5.61646655^{* *}$ \\
\hline miR5830 & $-4.18762998^{* *}$ & $5.11294928^{* *}$ \\
\hline miR395 & $10.30345436^{* *}$ & $4.61153607^{* *}$ \\
\hline miR5210 & $-3.03780053^{* *}$ & $4.38945452^{* *}$ \\
\hline miR3437 & $-4.38720917^{* *}$ & $3.97352136^{* *}$ \\
\hline miR5304 & $4.5270768^{* *}$ & $3.11469877^{* *}$ \\
\hline miR7485 & $2.08344945^{* *}$ & $1.63183983^{* *}$ \\
\hline miR5818 & $-4.95063483^{* *}$ & $1.50697816^{* *}$ \\
\hline miR1222 & $-2.88894979^{* *}$ & $-13.23073355^{* *}$ \\
\hline miR6425 & $-5.81634371^{* *}$ & $-10.19869057^{* *}$ \\
\hline miR3438 & $7.67399457^{* *}$ & $-9.31063262^{* *}$ \\
\hline miR7708 & $-10.0710064^{* *}$ & $-8.18079862^{* *}$ \\
\hline miR5290 & $4.73213099 * *$ & $-7.59506455^{* *}$ \\
\hline miR6247 & $-9.56671537^{* *}$ & $-6.67041637^{* *}$ \\
\hline miR2616 & $6.25578869^{* *}$ & $-4.06995485^{* *}$ \\
\hline miR5286 & $6.7663942^{* *}$ & $-3.78538232^{* *}$ \\
\hline miR6426 & $4.30631516^{* *}$ & $-1.65860955^{* *}$ \\
\hline miR812 & $7.83035956^{* *}$ & $-1.64980601^{* *}$ \\
\hline
\end{tabular}

Data from Additional file 3 and Ma et al. [36]; **indicates a significant difference at $P<0.01$

to different abnormalities in root morphogenesis in Arabidopsis mutant. Nuclear pore complex protein NUP88 is necessary for systemic acquired resistance and $R$ protein-mediated defense [73]. The induction of root NUP88 by Mg-deficiency (Table 2) agrees with the above inference that that disease-resistance was improved in Mg-deficient roots.

Root miR1044 was repressed and its target genes [i.e., NF-X-like 1 (NFXL1), POD superfamily protein and ATPase, AAA-type, CDC48 protein] were induced by Mg-deprivation except for integrase-type DNA-binding superfamily protein (Table 2). Lisso et al. [74] observed that AtNFXL1 was induced in roots under salt and osmotic stress, and that both AtNFXL1-antisense plants and atnfxl1-1 knock-out mutants had lower growth and survival rates than wild-type plants when exposed to salt or osmotic stress. CDC48, a member of AAA-ATPase family proteins that provides energy for plant development via regulating ATPase, is required for plant cell division, expansion and differentiation [75]. Wang et al. [76] suggested that the induction of PpCDC48II by low temperature played a key role in cold-induced freezing tolerance of Physcomitrella patens cells.

MiR5261 and its target genes were repressed and induced in Mg-starved roots, respectively (Table 2). The induction of root RNA binding (RRM/RBD/RNP motifs) family protein by $\mathrm{Mg}$-deficiency agrees with our report that the abundance of RNA binding (RRM/RBD/RNP motifs) family protein was elevated in B-deficient roots [60]. A typical mitogen-activated protein kinase (MAPK) cascade is composed of three sequentially activated protein kinases, namely MAPK, MAPK kinase (MAPKK) and MAPKK kinase (MAPKKK). Stress-tolerance of some plants such as Arabidopsis, tobacco and cereals has been enhanced by genetically altering the abundances and/or the activities of some MAPK components $[77,78]$. The induction of root protein phosphatase $2 A$ (PP2A) regulatory $B$ subunit family protein by $\mathrm{Mg}$ deficiency (Table 2) agrees with the report that wheat root $P P 2 A b B^{\prime \prime}-\alpha$ was up-regulated when exposed to various abiotic stresses. Transgenic wheat lines overexpressing TaPP2AbB"- $\alpha$ displayed better lateral root development, especially under $\mathrm{NaCl}$ and mannitol stresses [79].

Ubiquitination-proteasomal pathway has been shown to function in plant senescence and in stress response by facilitating the degradation of bulk proteins for $\mathrm{N}$ recycling [80]. Transgenic tobacco lines over-expressing a maize gene encoding E3 ubiquitin ligase (UPL) displayed increased drought tolerance accompanied by higher activities of superoxide dismutase (SOD) and catalase, more accumulation of proline and less accumulation of malondialdehyde (MDA) and ROS when exposed to drought stress [81]. Over-expression of TaFBA1 encoding F-box protein conferred drought and oxidative stress tolerance in tobacco plants via up-regulating the activities of SOD, catalase, ascorbate peroxidase (APX) and POD, and lowering the levels of ROS and MDA [82, 83]. Thus, up-regulation of UPL1 and RING/U-box superfamily protein targeted by miR5261, NFXL1 targeted by miR1044, F-box family protein targeted by miR1151 and proteasome subunit beta type-6 (PBA1) targeted by miR5029 in Mg-starved roots (Table 2) might confer stress-tolerance, thus contributing to Mg-deficiency tolerance in Citrus plants. Similarly, the expression levels of UPL5 (XP 003594229.1) and F-box family protein (XP 
003612153.1) in C. reticulata roots [13] and the abundances of putative proteasome subunit alpha type (gi|255,584,432) in C. sinensis roots [12] were elevated by Mg-deficiency.

\section{Conclusions}

For the first time, we used Illumina sequencing to identify 71 known and 30 novel miRNAs with increased expressed, and 54 known and 15 novel miRNAs with decreased expression in Mg-deficient C. sinensis roots, demonstrating that miRNAs might be involved in Citrus Mg-deficiency tolerance. Through integrating our findings with the previous data, we put forward a potential scheme for the responses of miRNAs to Mgdeficiency in Citrus roots (Fig. 5). Here, we obtained several novel Mg-deficiency-responsive miRNAs (i.e., miR5261, miR158, miR6190, miR6485, miR1151 and miR1044) possibly responsible for Citrus $\mathrm{Mg}$-deficiency tolerance. Our findings results not only increased our knowledge on the functions of plant miRNAs under nutrient deficiencies, but also established foundation to improve Mg-deficiency tolerance via manipulating the actions of miRNAs.

\section{Methods}

\section{Citrus sinensis Seedling culture and long-term Mg-} deficient treatments

Seedling culture and long-term Mg-deficient treatments were carried out as described previously [12]. In short, 15-week-old 'Xuegan' [Citrus sinensis (L.) Osbeck] seedlings, which were grown in $6 \mathrm{~L}$ pots (two seedlings per pot) filled with clean river sand in a greenhouse under natural photoperiod at Fujian Agriculture and Forestry University, Fuzhou, were supplied every other day until dripping with nutrient solution at a $\mathrm{Mg}$ concentration of
$0 \mathrm{mM}$ (Mg-deficiency) or $1 \mathrm{mM}$ (Mg-sufficiency, control) from $\mathrm{MgSO}_{4}$. S at the nutrient solution was kept at a constant level by adding equivalent moles of $\mathrm{Na}_{2} \mathrm{SO}_{4}$ in replace of $\mathrm{MgSO}_{4}$. After 16 weeks, 5-mm-long root apices from new white fibrous roots were harvested and immediately frozen in liquid $\mathrm{N}_{2}$, then stored at $-80{ }^{\circ} \mathrm{C}$ until extraction. The seedlings not being sampled were used for the measurements of root DW, leaf and root Mg.

\section{Root DW and root and leaf $\mathrm{Mg}$}

For each treatment, roots from nine seedlings (one seedling per pot) were taken. Root DW was measured after being dried at $70{ }^{\circ} \mathrm{C}$ to a constant weight $(\sim 48 \mathrm{~h})$.

Fibrous roots and $\sim 7$-week-old leaves (midribs and petioles removed) were harvested and then dried at $70{ }^{\circ} \mathrm{C}$ to a constant weight. Dried roots and leaves were ground to pass a 40 mesh sieve, finally digested with $1 \mathrm{~N} \mathrm{HCl}$ [84]. $\mathrm{Mg}$ concentration in the solution was measured by atomic absorption spectroscopy.

\section{Root sRNAs library construction, high-throughput sequencing, annotation and miRNA identification}

Equal amounts of frozen root apices from five seedlings (one seedling per pot) were pooled as a biological replicate. There was one biological replicate for each treatment. Approximately $0.1 \mathrm{~g}$ mixed frozen $\mathrm{Mg}$-deficient or control root apices were used to extract total RNA with TRIzol reagent (Invitrogen, Carlsbad, CA). Construction of sRNA libraries was performed as described by $\mathrm{Lu}$ et al. [17]. Illumina sequencing was carried out with a Solexa sequencer at the Beijing Genomics Institute (BGI), Shenzhen, China.

Both sRNA annotation and miRNA identification were made as described previously $[17,18]$. After raw data being analyzed with a software developed by BGI, clean

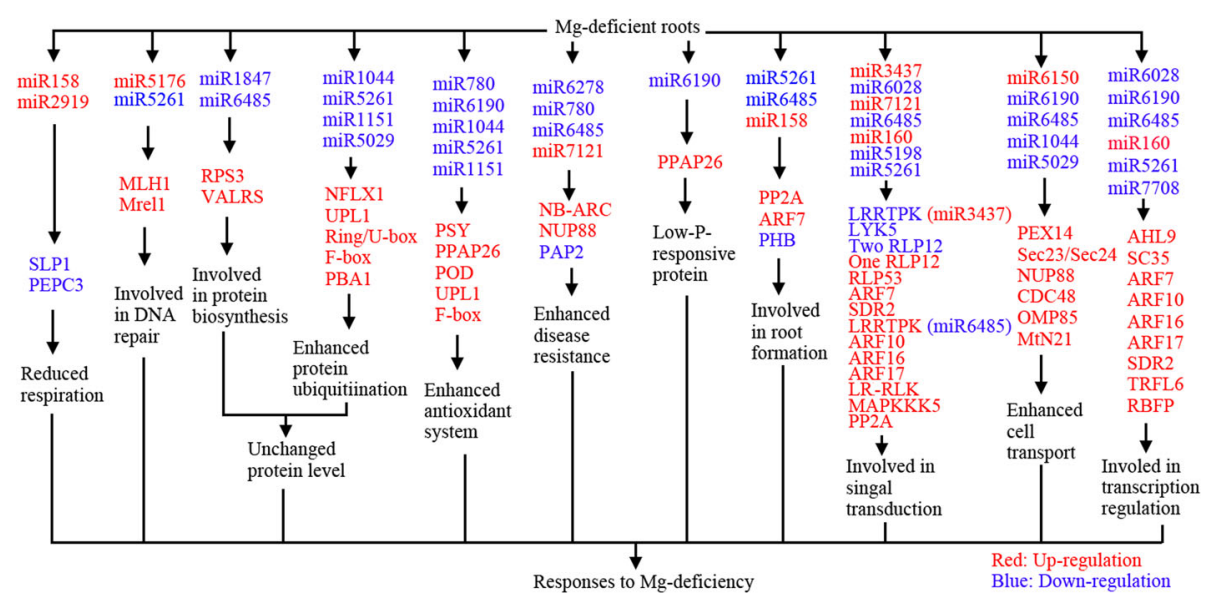

Fig. 5 A potential scheme for responses of C. sinensis roots miRNAs to Mg-deficiency. LRRTPK: Leucine-rich repeat transmembrane protein kinase; LYK5: LysM-containing receptor-like kinase 5; PEX14: Peroxin 14; RBFP: RNA binding (RRM/RBD/RNP motifs) family protein; RLP: Receptor like protein; RPS3: Ribosomal protein S3 family protein; WRKY72: WRKY DNA-binding protein 72 
reads were then utilized to assay length distribution. Finally, the clear reads were mapped to $C$. sinensis genome (JGIversion 1.1, http://phytozome.jgi.doe.gov/pz/ portal.html\#!info?alias=Org_Csinensis) using SOAP, only perfectly mapped sequences were retained and analyzed further. rRNAs, tRNAs, snRNAs and snoRNAs were removed from the sRNAs sequences through BLASTn search using NCBI Genebank database (http:// www.ncbi.nlm.nih.gov/blast/Blast.cgi/) and Rfam (12.0) database (http://www.sanger.ac.uk/resources/databases/ rfam.html $)(e=0.01)$. The remaining sequences were aligned with known plant miRNAs from miRBase 21 (http://www.mirbase.org/). Only the perfectly matched sequences were considered to be conserved miRNAs. Reads not being annotated were used for the prediction of novel miRNAs using Mireap (http://sourceforge.net/ projects/mireap/), a software developed by BGI. Also, both DNAMAN 8 (http://www.lynnon.com/pc/framepc.html) and MTide (http://bis.zju.edu.cn/MTide) [85] were used for the prediction of novel miRNAs. Only these miRNA candidates being simultaneously predicted by the three softwares were regarded to be novel miRNAs.

\section{Differentially expressed miRNAs and target prediction}

Both the fold change between Mg-deficient and -sufficient roots and the $P$-value were calculated from the normalized expression of TPM [86]. A miRNA was regarded to be differentially expressed when it had both a $P$-value $<0.01$ and a $\log 2$-fold change $>1.5$ [17]. Target prediction of miRNAs was carried out by RNAhybrid according to the rules proposed by Schwab et al. [87] and Allen et al. [88].

\section{Categories of the potential targets predicted from Mg- deficiency-responsive miRNAs}

All target genes predicted from Mg-deficiency-responsive miRNAs were mapped to $\mathrm{GO}$ terms in the database (http://www.geneontology.org/), and gene numbers for each term was calculated. All these targets were grouped into three categories: biological process, molecular function, cellular component [17].

\section{Validation of Mg-deficiency-responsive miRNAs by stem- loop qRT-PCR and of target genes by qRT-PCR}

Stem-loop qRT-PCR analysis of miRNAs was carried out as described previously [18]. Stem-loop primers for reverse transcription and primers for qRT-PCR were summarized in Additional file 9. qRT-PCR analysis of target genes was carried out with an ABI 7500 Real Time System as described by Lu et al. [17]. The sequences of the $\mathrm{F}$ and $\mathrm{R}$ primers used were given in Additional file 10 . Equal amounts of frozen root apices from five seedlings (one seedling per pot) were pooled as a biological replicate. For each treatment, there were three biological replicates and two technical replicates. Relative miRNA expression was calculated using ddCt algorithm. Actin (AEK97331.1) was used as an internal standard and the roots from $\mathrm{Mg}$-sufficient seedlings were used as reference sample, which was set to 1 .

\section{Experimental design and data analysis}

For each treatment, there were 20 pot seedlings in a completely randomized design. Experiments were carried out with 3 replicates except for high-throughput sequencing $(n=1)$, root and leaf $\mathrm{Mg}(n=5)$, and root DW $(n=9)$. Unpaired $t$-test was performed for the significant test between two means (Mg-sufficiency and -deficiency).

\section{Additional files}

Additional file 1: List of known miRNAs in C. sinensis roots. (DOC $995 \mathrm{~kb}$ )

Additional file 2: List of known miRNAs in C. sinensis roots after removing these miRNAs with normalized read-count less than 10 TPM in the two miRNA libraries constructed from Mg-sufficient and -deficient roots. (DOC $447 \mathrm{~kb}$ )

Additional file 3: List of Mg-deficiency-responsive known miRNAs in C. sinensis roots. (DOC $205 \mathrm{~kb}$ )

Additional file 4: List of novel miRNAs in C. sinensis roots. (DOC $288 \mathrm{~kb}$ ) Additional file 5: List of novel miRNAs in C. sinensis roots after removing these miRNAs with normalized read-count less than 10 TPM in the two miRNA libraries constructed from Mg-sufficient and -deficient roots. (DOC $160 \mathrm{~kb})$

Additional file 6: List of Mg-deficiency-responsive novel miRNAs in C. sinensis roots. (DOC $105 \mathrm{~kb}$ )

Additional file 7: List of target genes for parts of known miRNAs in C. sinensis roots. (DOC $262 \mathrm{~kb}$ )

Additional file 8: List of target genes for parts of novel miRNAs in C. sinensis roots. (DOCX $25 \mathrm{~kb})$

Additional file 9: Stem loop primer sequences for qRT-PCR analysis of miRNAs. (DOCX $17 \mathrm{~kb}$ )

Additional file 10: Specific primer pairs used for qRT-PCR expression analysis of selected miRNA target genes. (DOCX $31 \mathrm{~kb}$ )

\section{Abbreviations}

AHL9: AT-hook motif nuclear-localized protein 9; APase: Acid phosphatase; APX: Ascorbate peroxidase; ARF: Auxin responsive factor; Car: Carotenoid; CDC48: A member of AAA-ATPase family proteins; COPII: Coat protein complex II; ER: endoplasmic reticulum; eTMs: Endogenous target mimics; LR-RLK: Leucine-rich receptor-like protein kinase; MAPK: Mitogen-activated protein kinase; MAPKK: MAPK kinase; MAPKKK: MAPKK kinase; MDA: Malondialdehyde; Mg: Magnesium; MLH1: MUTL-homologue 1; MMR: DNA mismatch repair; NUP88: Nuclear pore complex protein; NFXL1: NF-X-like 1; NLA: Nitrogen limitation adaptation; PAP: Phosphatidic acid phosphatase; PBA1: Proteasome subunit beta type-6; PEPC: Phosphoenolpyruvate carboxylase; PHB: Prohibitin;

PLA2A: Phospholipase A 2A; POD: Peroxidase; PP2A: Protein phosphatase 2A; PPAP: Purple acid phosphatase; PSY: Phytoene synthase; ROS: Reactive oxygen species; SC35: Ortholog of human splicing factor; SDR2: SnRNA activating complex family protein; SLP1: Stomatin-like protein 1; SOD: Superoxide dismutase; SPFH: Stomatins, prohibitins, flotillins and HfIK/C; TPM: Transcript per million; UCB24: Ubiquitin-conjugating enzyme E2 24; UPL1: Ubiquitin-protein ligase 1 (E3 ubiquitin-protein ligase UPL1); VALRS: Valyl-tRNA synthetase / valine-tRNA ligase. 


\section{Acknowledgements}

Not applicable.

\section{Funding}

This study was supported by the National Natural Science Foundation of China (No. 31572081), the Natural Science Foundation of Fujian Province, China (No. 2016 J01115) and the earmarked fund for China Agriculture Research System (No. CARS-27). The funding bodies had no role in the design, collection and interpretation of data or the manuscript writing.

\section{Availability of data and materials}

All data generated or analyzed during this study are included in this published article [and its supplementary information files]. Primary RNA-Seq data are submitted to Gene Expression Omnibus (GEO) under accession number GSE80713 (http://www.ncbi.nlm.nih.gov/geo/query/ acc.cgi?acc=GSE80713).

\section{Authors' contributions}

WWL carried out most of the experiment, analyzed the data and drafted the manuscript; JHH and LTY participated in the direction of this study; CPL and XY participated in the measurement of $\mathrm{Mg}$ and data analysis; $\mathrm{DL}$ participated in the cultivation of seedlings and QRT-PCR analysis; LSC designed and directed the study and revised the manuscript. All authors have read and approved the final manuscript.

\section{Ethics approval and consent to participate}

Citrus sinensis seeds, which were public and available for non-commercial purpose, were collected from Minan village, Tingjiang town, Mawei district, Fuzhou city, China. Collection of seeds complied with the institutional, national and international guidelines. No specific permits were required.

\section{Consent for publication}

Not applicable.

\section{Competing interests}

The authors declare that they have no competing interests.

\section{Publisher's Note}

Springer Nature remains neutral with regard to jurisdictional claims in published maps and institutional affiliations.

\section{Author details \\ 'Institute of Plant Nutritional Physiology and Molecular Biology, College of Resources and Environment, Fujian Agriculture and Forestry University, Fuzhou 350002, China. ${ }^{2}$ Pomological Institute, Fujian Academy of Agricultural Sciences, Fuzhou 350013, China. ${ }^{3}$ Fujian Provincial Key Laboratory of Soil Environmental Health and Regulation, College of Resources and Environment, Fujian Agriculture and Forestry University, Fuzhou 350002 China. ${ }^{4}$ The Higher Educational Key Laboratory of Fujian Province for Soil Ecosystem Health and Regulation, Fujian Agriculture and Forestry University, Fuzhou 350002, China.}

Received: 5 June 2016 Accepted: 1 August 2017

Published online: 24 August 2017

\section{References}

1. Hopkins WG, Hüner NPA. Introduction to plant physiology. 4th ed. New York: John Wiley \& Sons, Inc.; 2008.

2. Ling LL, Peng LZ, Cao L, Jiang CL, Chun CP, Zhang GY, Wang ZX. Effect of magnesium deficiency on photosynthesis characteristic of Beibei 447 Jinchen orange. J Fruit Sci. 2009;26:275-80.

3. Li Y, Han MQ, Lin F, Ten Y, Lin J, Zhu DH, Guo P, Weng YB, Chen LS. Soil chemical properties, 'Guanximiyou' pummelo leaf mineral nutrient status and fruit quality in the southern region of Fujian province. China J Soil Sci Plant Nutr. 2015;15:615-28.

4. Guo W, Hussain H, Liang Z, Yang D. Magnesium deficiency in plants: An urgent problem. Crop J. 2016;4:83-91.

5. Tang N, Li Y, Chen LS. Magnesium deficiency-induced impairment of photosynthesis in leaves of fruiting Citrus reticulata trees accompanied by up-regulation of antioxidant metabolism to avoid photooxidative damage. J Plant Nutr Soil Sci. 2012;175:784-93.
6. Yang GH, Yang LT, Jiang HX, Wang P, Chen LS. Physiological impacts of magnesium-deficiency in Citrus seedlings: photosynthesis, antioxidant system and carbohydrates. Trees Struct Funct. 2012;26:1237-50.

7. Li CP, Qi YP, Zhang J, Yang LT, Wang DH, Ye X, Lai NW, Tan LL, Lin D, Chen LS. Magnesium-deficiency-induced alterations of gas exchange, major metabolites and key enzymes differ among roots, lower and upper leaves of Citrus sinensis seedlings. Tree Physiol. 2017;DOI: 10.1093/treephys/tpx067

8. Cowan JA. Structural and catalytic chemistry of magnesium-dependent enzymes. Biometals. 2002;15:225-35.

9. Cakmak I, Kirkby EA. Role of magnesium in carbon partitioning and alleviating photooxidative damage. Physiol Plant. 2008;133:692-704.

10. Verbruggen $\mathrm{N}$, Hermans C. Physiological and molecular responses to magnesium nutritional imbalance in plants. Plant Soil. 2013;368:87-99.

11. Cakmak I, Yazici AM. Magnesium: a forgotten element in crop production. Better Crops. 2010:94:23-5.

12. Peng HY, Qi YP, Lee J, Yang LT, Guo P, Jiang HX, Chen LS. Proteomic analysis of Citrus sinensis roots and leaves in response to long-term magnesium-deficiency. BMC Genomics. 2015;16:253.

13. Jin $\mathrm{XL}, \mathrm{Ma} \mathrm{CL}$, Yang LT, Chen LS. Alterations of physiology and gene expression due to long-term magnesium-deficiency differ between leaves and roots of Citrus reticulata. J Plant Physiol. 2016;198:103-15.

14. Shukla LI, Chinnusamy V, Sunkar R. The role of microRNAs and other endogenous small RNAs in plant stress responses. Biochim Biophys Acta. 2008; 1779:743-8.

15. Khraiwesh B, Zhu JK, Zhu J. Role of miRNAs and siRNAs in biotic and abiotic stress responses of plants. Biochim Biophys Acta. 1819;2012:137-48.

16. Kulcheski FR, Côrrea R, Gomes IA, de Lima JC, Margis R. NPK macronutrients and microRNA homeostasis. Front Plant Sci. 2015;6:451.

17. Lu YB, Yang LT, Qi YP, Li Y, Li Z, Chen YB, Huang ZR, Chen LS. Identification of boron-deficiency-responsive microRNAs in Citrus sinensis roots by lllumina sequencing. BMC Plant Biol. 2014;14:123.

18. Lu YB, Qi YP, Yang LT, Guo P, Li Y, Chen LS. Boron-deficiency-responsive microRNAs and their targets in Citrus sinensis leaves. BMC Plant Biol. 2015;15:271.

19. Paul S, Datta SK, Datta K. MiRNA regulation of nutrient homeostasis in plants. Front Plant Sci. 2015;6:232.

20. Zeng $H$, Wang G, Hu X, Wang H, Du L, Zhu Y. Role of microRNAs in plant responses to nutrient stress. Plant Soil. 2014:374:1005-21.

21. Branscheid A, Sieh D, Pant BD, May P, Devers EA, Elkrog A, Schauser L, Scheible WR, Krajinski F. Expression pattern suggests a role of miR399 in the regulation of the cellular response to local pi increase during arbuscular mycorrhizal symbiosis. Mol Plant-Microbe Interact. 2010;23:915-26.

22. Gu M, Xu K, Chen A, Zhu Y, Tang G, Xu G. Expression analysis suggests potential roles of microRNAs for phosphate and arbuscular mycorrhizal signaling in Solanum lycopersicum. Physiol Plant. 2010;138:226-37.

23. Hsieh LC, Lin SI, Shih ACC, Chen JW, Lin WY, Tseng CY, Li WH, Chiou TJ, Uncovering small RNA-mediated responses to phosphate deficiency in Arabidopsis by deep sequencing. Plant Physiol. 2009;151:2120-32.

24. Nguyen GN, Rothstein SJ, Spangenberg G, Kant S. Role of microRNAs involved in plant response to nitrogen and phosphorous limiting conditions. Front Plant Sci. 2015;6:629.

25. Valdés-López O, Yang SS, Aparicio-Fabre R, Graham PH, Reyes IL, Vance CP, Hernández G. MicroRNA expression profile in common bean (Phaseolus vulgaris) under nutrient deficiency stresses and manganese toxicity. New Phytol. 2010;187:805-18.

26. Chiou TJ. The role of microRNAs in sensing nutrient stress. Plant Cell Environ. 2007:30:323-32.

27. Liu TY, Lin WY, Huang TK, Chiou TJ. MicroRNA-mediated surveillance of phosphate transporters on the move. Trends Plant Sci. 2014:19:647-55.

28. Liang G, He H, Yu D. Identification of nitrogen starvation-responsive microRNAs in Arabidopsis thaliana. PLoS One. 2012;7:e48951.

29. Zhao M, Tai H, Sun S, Zhang F, Xu Y, Li WX. Cloning and characterization of maize miRNAs involved in responses to nitrogen deficiency. PLoS One. 2012:7:e29669.

30. Zhao M, Ding H, Zhu JK, Zhang F, Li WX. Involvement of miR169 in the nitrogen-starvation responses in Arabidopsis. New Phytol. 2011;190:906-15.

31. Yan Y, Wang H, Hamera S, Chen X, Fang R. MiR444a has multiple functions in the rice nitrate-signaling pathway. Plant J. 2014;78:44-55.

32. Abdel-Ghany SE, Pilon M. MicroRNA-mdiated systemic down-regulation of copper protein expression in response to low copper availability in Arabidopsis. J Biol Chem. 2008;283:15932-45. 
33. Waters BM, Mclnturf SA, Stein RJ. Rosette iron deficiency transcript and microRNA profiling reveals links between copper and iron homeostasis in Arabidopsis thaliana. J Exp Bot. 2012;63:5903-18.

34. Liang G, Yang F, Yu D. MicroRNA395 mediates regulation of sulfate accumulation and allocation in Arabidopsis thaliana. Plant J. 2010;62:1046-57.

35. Li Y, Zhang Y, Shi D, Liu X, Qin J, Ge Q, Xu L, Pan X, Li W, Zhu Y, Xu J. Spatial-temporal analysis of zinc homeostasis reveals the response mechanisms to acute zinc deficiency in Sorghum bicolor. New Phytol. 2013;200:1102-15.

36. Ma CL, Qi YP, Yang LT, Lu YB, Guo P, Ye X, Chen LS. MicroRNA regulatory mechanisms on Citrus sinensis leaves to magnesium-deficiency. Front Plant Sci. 2016;7:201.

37. Chapman HD. The mineral nutrition of Citrus. In: Reuther W, Webber HJ, Batchelor LD, editors. The Citrus industry, vol. 2. CA: Division of Agricultural Sciences, University of California; 1968. p. 127-89.

38. Xu Q, Liu Y, Zhu A, Wu X, Ye J, Yu K, Guo W, Deng X. Discovery and comparative and comparative profiling of microRNAs in a sweet orange red-flesh mutant and its wild type. BMC Genomics. 2010;11:246.

39. Song C, Wang C, Zhang C, Korir NK, Yu H, Ma Z, Fang J. Deep sequencing discovery of novel and conserved microRNAs in trifoliate orange (Citrus trifoliata). BMC Genomics. 2010:11:431.

40. Li R, Li Y, Kristiansen K, Wang J. SOAP: short oligonucleotide alignment program. Bioinformatics. 2008;24:713-4.

41. Chen L, Wang T, Zhao M, Tian Q, Zhang WH. Identification of aluminumresponsive microRNAs in Medicago truncatula by genome-wide highthroughput sequencing. Planta. 2012;235:375-86.

42. Huang JH, Qi YP, Wen SX, Guo P, Chen XM, Chen LS. Illumina microRNA profiles reveal the involvement of miR397a in Citrus adaptation to longterm boron toxicity via modulating secondary cell-wall biosynthesis. Sci Rep. 2016;6:22900.

43. Hermans C, Conn SJ, Chen J, Xiao Q, Verbruggen N. An update on magnesium homeostasis mechanisms in plants. Metallomics. 2013;5:1170-83.

44. Wang Y, Ries A, Wu K, Yang A, Crawford NM. The Arabidopsis prohibitin gene $P H B 3$ functions in nitric oxide-mediated responses and in hydrogen peroxide-induced nitric oxide accumulation. Plant Cell. 2010;22:249-59.

45. Gehl B, Lee CP, Bota P, Blatt MR, Sweetlove LJ. An Arabidopsis stomatin-like protein affects mitochondrial respiratory supercomplex organization. Plant Physiol. 2014;164:1389-400.

46. Xu J. Effects of magnesium deficiency on Citrus elements and root and leaf anatomical structures, Master thesis. Fuzhou: Fujian Agriculture and Forestry University, Fuzhou; 2015.

47. Amtmann A, Troufflard S, Armengaud P. The effect of potassium nutrition on pest and disease resistance in plants. Physiol Plant. 2008;133:682-91.

48. Huber DM, Jones JB. The role of magnesium in plant disease. Plant Soil. 2013;368:73-85.

49. Guleria P, Yadav SK. Identification of miR414 and expression analysis of conserved miRNAs from Stevia rebaudiana. Genomics Proteomics Bioinformatics. 2011;9:211-7.

50. Galles C, Spampinato CP. Yeast mutator phenotype enforced by Arabidopsis PMS1 expression. Mol Biol Rep. 2013;40:2107-14.

51. Dion E, Li L, Jean M, Belzile F. An Arabidopsis MLH1 mutant exhibits reproductive defects and reveals a dual role for this gene in mitotic recombination. Plant J. 2007;51:431-40.

52. Dievart A, Perin C, Hirsch J, Bettembourg M, Lanau N, Artus F, Bureau C, Noel N, Droc G, Peyramard M, Pereira S, Courtois B, Morel JB, Guiderdoni E. The phenome analysis of mutant alleles in leucine-rich repeat receptor-like kinase genes in rice reveals new potential targets for stress tolerant cereals. Plant Sci. 2016;242:240-9.

53. Rodríguez-Villalón A, Gas E, Rodríguez-Concepción M. Phytoene synthase activity controls the biosynthesis of carotenoids and the supply of their metabolic precursors in dark-grown Arabidopsis seedlings. Plant J. 2009;60:424-35.

54. Zhang J, Tao N, Xu Q, Zhou W, Cao H, Xu J, Deng X. Functional characterization of Citrus PSY gene in Hongkong kumquat (Fortunella hindsii Swingle). Plant Cell Rep. 2009;28:1737-46.

55. Nakano M, Nishihara M, Yoshioka H, Takahashi H, Sawasaki T, Ohnishi K, Hikichi Y, Kiba A. Suppression of DS1 phosphatidic acid phosphatase confirms resistance to Ralstonia solanacearum in Nicotiana benthamiana. PLoS One. 2013;8:e75124.

56. Duque P. A role for SR proteins in plant stress responses. Plant Signal Behav. $2011 ; 6: 49-54$
57. Hurley BA, Tran HT, Marty NJ, Park J, Snedden WA, Mullen RT, Plaxton WC. The dual-targeted purple acid phosphatase isozyme AtPAP26 is essential for efficient acclimation of Arabidopsis to nutritional phosphate deprivation. Plant Physiol. 2010;153:1112-22.

58. Veljanovski V, Vanderbeld B, Knowles VL, Snedden WA, Plaxton WC. Biochemical and molecular characterization of AtPAP26, a vacuolar purple acid phosphatase up-regulated in phosphate-deprived Arabidopsis suspension cells and seedlings. Plant Physiol. 2006;142:1282-93.

59. Malhotra $V$, Erlmann P. Protein export at the ER: loading big collagens into COPII carriers. EMBO J. 2011;30:3475-80.

60. Yang LT, Qi YP, Lu YB, Guo P, Sang W, Feng H, Zhang HX, Chen LS. iTRAQ protein profile analysis of Citrus sinensis roots in response to long-term boron-deficiency. J Proteome. 2013;93:179-206.

61. Mallory AC, Bartel DP, Bartel B. MicroRNA-directed regulation of Arabidopsis AUXIN RESPONSE FACTOR17 is essential for proper development and modulates expression of early auxin response genes. Plant Cell. 2005;17:1360-75.

62. Wang JW, Wang LJ, Mao YB, Cai WJ, Xue HW, Chen XY. Control of root cap formation by microRNA-targeted auxin response factors in Arabidopsis. Plant Cell. 2005;17:2204-16.

63. Liu PP, Montgomery TA, Fahlgren N, Kasschau KD, Nonogaki H, Carrington JC. Repression of AUXIN RESPONSE FACTOR10 by microRNA160 is critical for seed germination and post-germination stages. Plant J. 2007;52:133-46.

64. Li XP, Zeng QF, Zhang GS, Zhao J. GmMIR160A, a class of soybean microRNA gene, negatively regulates progress of leaf senescence. Guihaia. 2015;35:84-91.

65. Zhu YY, Zeng HQ, Dong CX, Yin XM, Shen QR, Yang ZM. MicroRNA expression profiles associated with phosphorus deficiency in white lupin (Lupinus albus L.). Plant Sci. 2010;178:23-9.

66. Xu Z, Zhong S, Li X, Li W, Rothstein SJ, Zhang S, Bi Y, Xie C. Genome-wide identification of microRNAs in response to low nitrate availability in maize leaves and roots. PLoS One. 2011;6:e28009.

67. Franco-Zorrilla JM1, Valli A, Todesco M, Mateos I, Puga MI, Rubio-Somoza I, Leyva A, Weigel D, García JA, Paz-Ares J. Target mimicry provides a new mechanism for regulation of microRNA activity. Nat Genet. 2007:39:1033-7.

68. Wu HJ, Wang ZM, Wang M, Wang XJ. Widespread long noncoding RNAs as endogenous target mimics for microRNAs in plants. Plant Physiol. 2013;161:1875-84

69. Lin $Y$, Lai Z, Tian $Q$, Lin L, Lai R, Yang M, Zhang D, Chen Y, Zhang Z. Endogenous target mimics down-regulate miR160 mediation of ARF10, -16 , and -17 cleavage during somatic embryogenesis in Dimocarpus longan lour. Front Plant Sci. 2015;6:956.

70. Li J, Dai X, Zhao Y. A role for auxin response factor 19 in auxin and ethylene signaling in Arabidopsis. Plant Physiol. 2006;140:899-908.

71. Okushima Y, Fukaki H, Onoda M, Theologis A, Tasaka M. ARF7 and ARF19 regulate lateral root formation via direct activation of $L B D / A S L$ genes in Arabidopsis. Plant Cell. 2007;19:118-30.

72. Ohtani M, Demura T, Sugiyama M. Particular significance of SRD2dependent snRNA accumulation in polarized pattern generation during lateral root development of Arabidopsis. Plant Cell Physiol. 2010;51:2002-12.

73. Cheng YT, Germain H, Wiermer M, Bi D, Xu F, García AV, Wirthmueller L, Després C, Parker JE, Zhang Y, Li X. Nuclear pore complex component MOS7/Nup88 is required for innate immunity and nuclear accumulation of defense regulators in Arabidopsis. Plant Cell. 2009;21:2503-16.

74. Lisso J, Altmann T, Müssig C. The AtNFXL1 gene encodes a NF-X1 type zinc finger protein required for growth under salt stress. FEBS Lett. 2006;580:4851-6.

75. Park S, Rancour DM, Bednarek SY. In planta analysis of the cell cycledependent localization of AtCDC48A and its critical roles in cell division, expansion, and differentiation. Plant Physiol. 2008;148:246-58.

76. Wang H, Jin S, Chen X, Gen XK, He YK. Target deletion of the AAA ATPase PpCDC48II in Physcomitrella patens results in freezing sensitivity after cold acclimation. Sci China Life Sci. 2012;55:150-7.

77. Šamajová O, Plíhal O, Al-Yousif M, Hirt H, Šamaj J. Improvement of stress tolerance in plants by genetic manipulation of mitogen-activated protein kinases. Biotechnol Adv. 2013;31:118-28.

78. Xing $Y$, Chen WH, Jia W, Zhang J. Mitogen-activated protein kinase kinase 5 (MKK5)-mediated signalling cascade regulates expression of iron superoxide dismutase gene in Arabidopsis under salinity stress. J Exp Bot. 2015;66:5971-81.

79. Liu D, Li A, Mao X, Jing R. Cloning and characterization of TaPP2AbB"-a, a member of the PP2A regulatory subunit in wheat. PLoS One 2014;9:e94430.

80. Zhou GA, Chang RZ, Qiu L. Overexpression of soybean ubiquitinconjugating enzyme gene GmUBC2 confers enhanced drought and salt 
tolerance through modulating abiotic stress-responsive gene expression in Arabidopsis. Plant Mol Biol. 2010;72:357-67.

81. Liu J, Xia Z, Wang M, Zhang X, Yang T, Wu J. Overexpression of a maize E3 ubiquitin ligase gene enhances drought tolerance through regulating stomatal aperture and antioxidant system in transgenic tobacco. Plant Physiol Biochem. 2013;73:114-20.

82. Zhou $S$, Sun $X$, Yin S, Kong X, Zhou S, Xu Y, Luo Y, Wang W. The role of the F-box gene TaFBA1 from wheat (Triticum aestivum $\mathrm{L}$.) in drought tolerance. Plant Physiol Biochem. 2014;84:213-23.

83. Zhou SM, Kong XZ, Kang HH, Sun XD, Wang W. The involvement of wheat F-box protein gene TaFBA1 in the oxidative stress tolerance of plants. PLoS One. 2015;10:e012211.

84. Kushizaki M. An extraction procedure of plant materials for the rapid determination of $\mathrm{Mn}, \mathrm{Cu}, \mathrm{Zn}$ and $\mathrm{mg}$ by the atomic absorption analysis. J Sci Soil Manure Japan. 1968:39:489-90

85. Zhang Z, Jiang L, Wang J, Gu P, Chen M. MTide: an integrated tool for the identification of miRNA-target interaction in plants. Bioinformatics. 2015;31:290-1.

86. Wang T, Chen L, Zhao M, Tian Q, Zhang WH. Identification of droughtresponsive microRNAs in Medicago truncatula by genome-wide high throughout sequencing. BMC Genomics. 2011;12:367.

87. Schwab R, Palatnik JF, Riester M, Schommer C, Schmid M. Specific effects of microRNAs on the plant transcriptome. Dev Cell. 2005;8:517-27.

88. Allen E, Xie Z, Gustafson AM, Carrington JC. MicroRNA-directed phasing during trans-acting siRNA biogenesis in plants. Cell. 2005;121:207-21.

\section{Submit your next manuscript to BioMed Central and we will help you at every step:}

- We accept pre-submission inquiries

- Our selector tool helps you to find the most relevant journal

- We provide round the clock customer support

- Convenient online submission

- Thorough peer review

- Inclusion in PubMed and all major indexing services

- Maximum visibility for your research

Submit your manuscript at www.biomedcentral.com/submit

) Biomed Central 